GENERALIZABILITY OF UNIVERSAL SCREENING MEASURES FOR BEHAVIORAL AND EMOTIONAL RISK

by

Nicholas Tanner

A Dissertation Submitted to the Faculty of the

DEPARTMENT OF DISABILITY AND PSYCHOEDUCATIONAL STUDIES

In Partial Fulfillment of the Requirements

For the Degree of

DOCTOR OF PHILOSOPHY

WITH A MAJOR IN SCHOOL PSYCHOLOGY

In the Graduate College

THE UNIVERSITY OF ARIZONA 


\section{THE UNIVERSITY OF ARIZONA COLLEGE OF EDUCATION}

As members of the Dissertation Committee, we certify that we have read the dissertation prepared by Nicholas Tanner, titled Generalizability of Universal Screening Measures for Behavioral and Emotional Risk and recommend that it be accepted as fulfilling the dissertation requirement for the Degree of Doctor of Philosophy.

Date: $4 / 25 / 16$

Katie Eklund, $\mathrm{PhD}$

Date: $4 / 25 / 16$

Stephen Kilgus, $\mathrm{PhD}$

Date: $4 / 25 / 16$

Jennifer Kirkpatrick, $\mathrm{PhD}$

Date: $4 / 25 / 16$

Michelle Perfect, $\mathrm{PhD}$

Final approval and acceptance of this dissertation is contingent upon the candidate's submission of the final copies of the dissertation to the Graduate College.

I hereby certify that I have read this dissertation prepared under my direction and recommend that it be accepted as fulfilling the dissertation requirement.

Dissertation Director: Katie Eklund, $\mathrm{PhD}$

Date: $4 / 25 / 16$ 


\section{STATEMENT BY AUTHOR}

This dissertation has been submitted in partial fulfillment of the requirements for an advanced degree at the University of Arizona and is deposited in the University Library to be made available to borrowers under rules of the Library.

Brief quotations from this dissertation are allowable without special permission, provided that an accurate acknowledgement of the source is made. Requests for permission for extended quotation from or reproduction of this manuscript in whole or in part may be granted by the head of the major department or the Dean of the Graduate College when in his or her judgment the proposed use of the material is in the interests of scholarship. In all other instances, however, permission must be obtained from the author.

SIGNED: Nicholas Tanner 


\section{ACKNOWLEDGEMENTS}

I am immensely grateful for my advisor, Dr. Katie Eklund, for her consistent dedication to my growth and development. Katie, the impact you have had on my professional identity is profound and appreciated. I simply could not have asked for a more supportive and thoughtful mentor.

I also warmly acknowledge the other members of my committee. Dr. Michelle Perfect, thank you for your encouragement throughout my graduate career, your dedication to science has been inspiring and has left a lasting influence on me. Dr. Stephen Kilgus, thank you for guidance in planting and tending to the seed that would eventually flower into this project. Lastly, I am indebted to Dr. Jennifer Kirkpatrick, for her thoughtful feedback, advice, and comments.

I would like to acknowledge the University of Arizona Graduate and Professional Student Council for their generous financial support of this project. I also recognize the effort of the primary participants in this study, the teachers, for their time and consideration as they filled out many surveys to ensure meaningful data was collected. Dr. Austin Johnson, your continued methodological support has strengthened this project.

I appreciate my friends and family for their help, encouragement, and perspective. Sara Frye, thank you for your support and friendship. I am grateful to my parents, Dennis and Jody Tanner, throughout the ups and downs, you have always advocated and believed in me. I dedicate this manuscript to my wife, Chelsea, for her affection, support, and countless hours editing that have made the past few years so much fun. 


\section{TABLE OF CONTENTS}

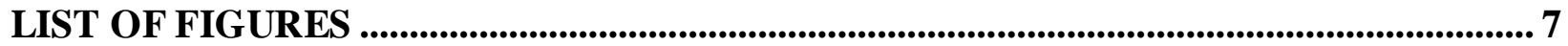

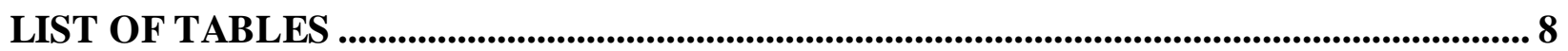

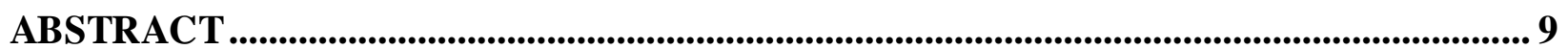

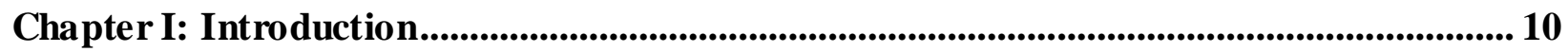

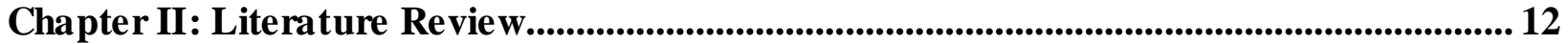

Identifying Students At-risk of Behavioral and Emotional Concerns ...................... 13

Universal Screening Procedures and Tools .......................................................................... 17

Multiple gating procedures. ............................................................................ 18

Teacher nomination. .......................................................................................................... 19

Office discipline referrals................................................................................ 20

Validity and Reliability in Unive rsal Screening ......................................................... 22

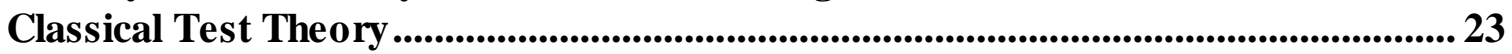

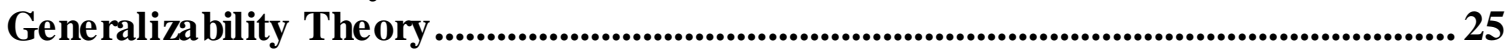

Scores and measurement. ............................................................................ 26

Assessing variance with generalizability theory ........................................... 28

Sources of measurement variance......................................................................... 30

Dependability and generalizability coefficients.............................................. 32

Generalizability Theory with Universal Screening for BER .......................................... 33

Generalizability theory and behavior rating scales.......................................... 33

Generalizability theory and brief behavior rating scales................................ 35

Summary and Conclusions................................................................................................ 36

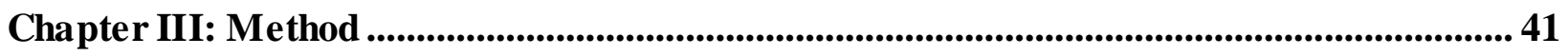

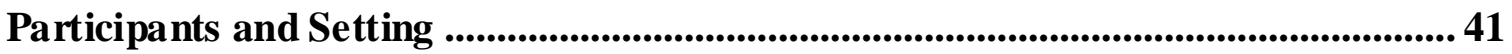

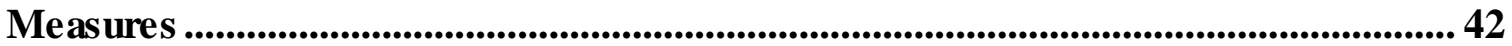

Social, Acade mic, and Emotional Behavior Risk Screener. ............................ 42

Strengths and Difficulties Questionnaire............................................................. 43

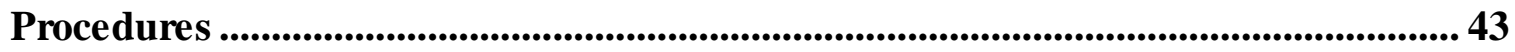

Recruitment. ................................................................................................................... 43

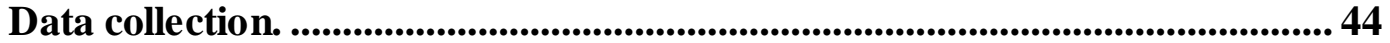

Data entry ve rification........................................................................................44 44

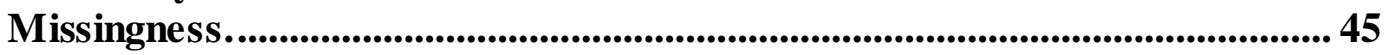

Data Analysis Plan ......................................................................................................... 45

Descriptive statistics and dichotomous analyses................................................. 45

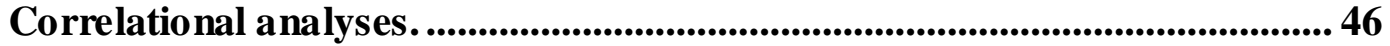

Generalizability analyses................................................................................ 46

Decision studies. ...............................................................................................5 50

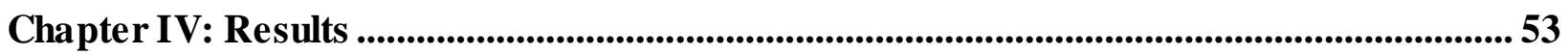

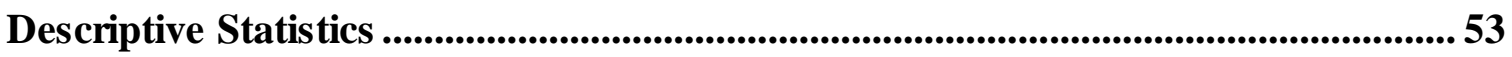

Dichotomous Variable Analyses ........................................................................................ 54

Individual base rates.................................................................................... 54

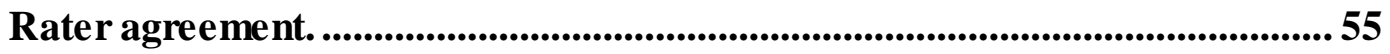

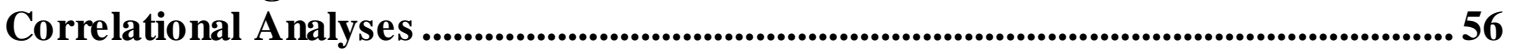

Test-retest reliability............................................................................................. 56 


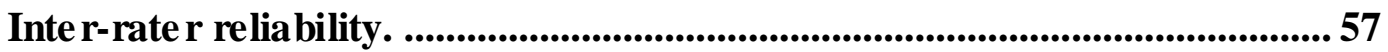

Concurre nt validity........................................................................................5 58

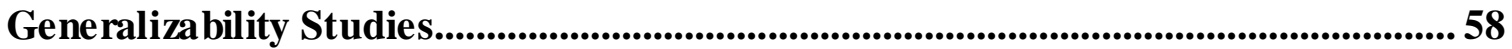

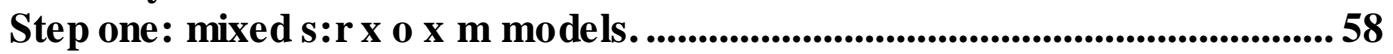

Step two: mixed s x rx ox m models. .............................................................6 61

Step three: random s $x$ r $x$ o models for SDQ and SAEBRS............................ 66

Comparing random $\mathrm{s} \times \mathrm{r} \times \mathrm{x}$ models............................................................................ 70

Decision Studies....................................................................................................... 71

Decision study for occasion on step two (mixed s x r x o x m) models........... 71

Decision study for rater on step two (mixed s x r x o x m) models................ 72

Decision study for occasion on step three (random s x r x o) models............. 72

Decision study for rater on step three (random s x r x o) models. .................. 73

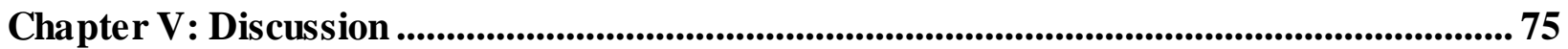

Research Question One: What is the test-retest, inter-rater reliability, and concurrent validity of BBRS? ............................................................................................... 76

Test-rest reliability....................................................................................................... 76

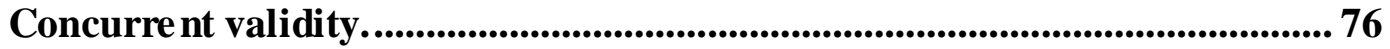

Inter-rater reliability. ............................................................................................... 76

Research Question Two: What proportion of variance in data derived from screening scores is attributable to differences between students, teachers, occasions, measures, and/or the inte ractions between these factors? ......................................... 77

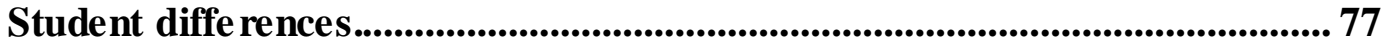

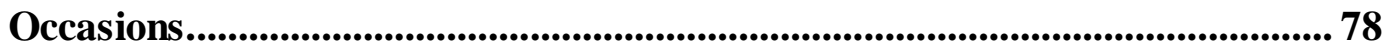

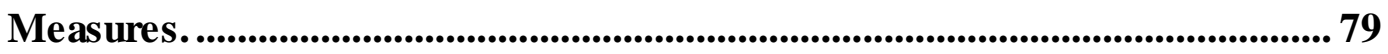

Teachers (rater)............................................................................................................... 79

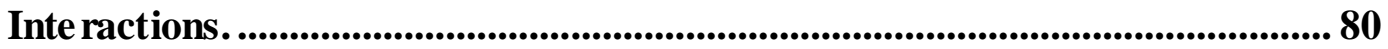

Research Question Three: How does altering the number of raters and occasions affect the generalizability of universal screening scores? .............................................8 81

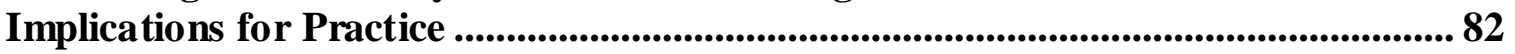

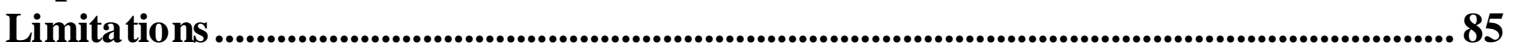

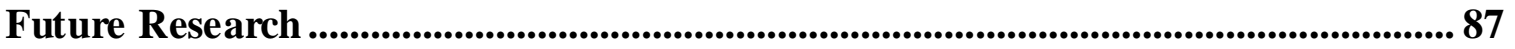

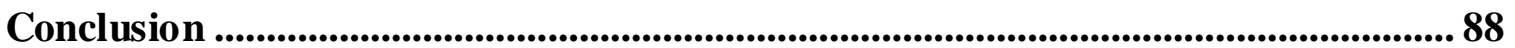

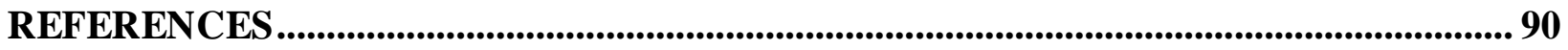




\section{LIST OF FIGURES}

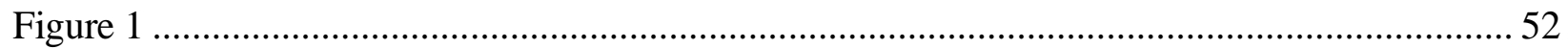




\section{LIST OF TABLES}

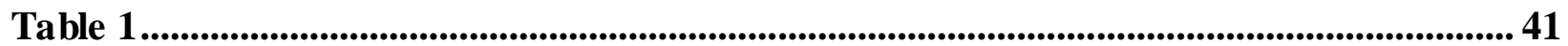

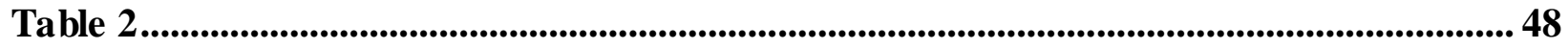

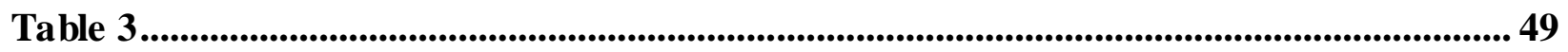

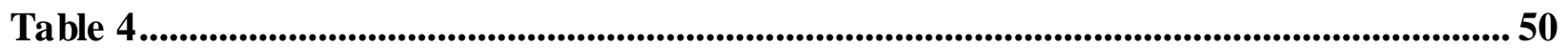

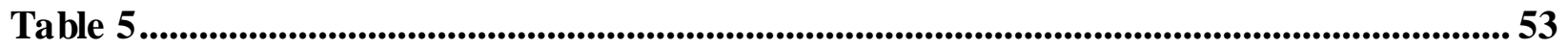

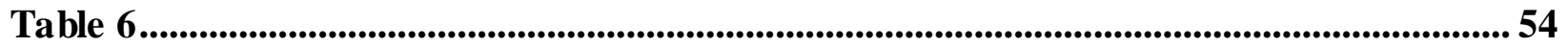

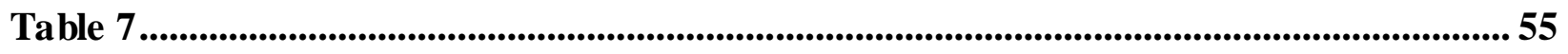

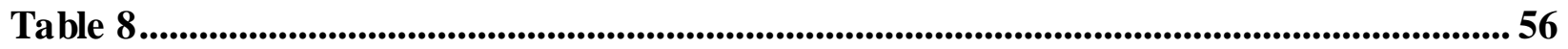

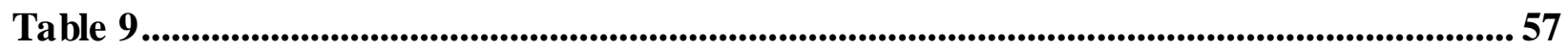

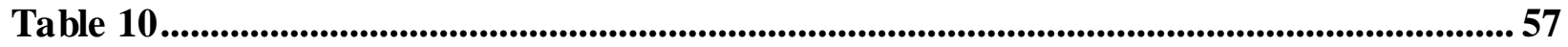

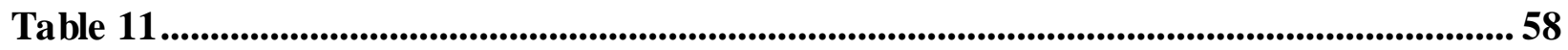

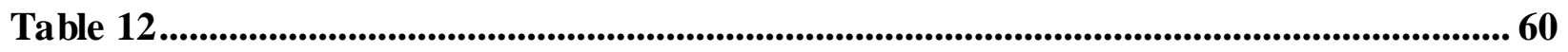

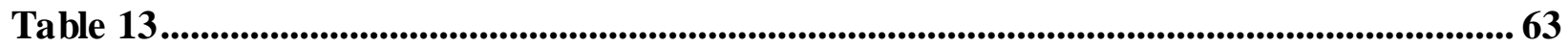

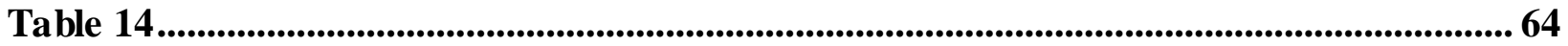

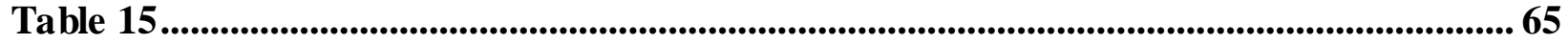

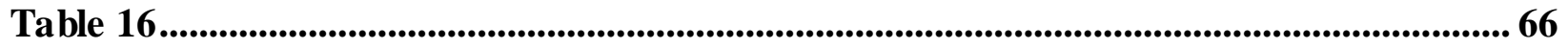

Table 17....................................................................................................................................................... 67

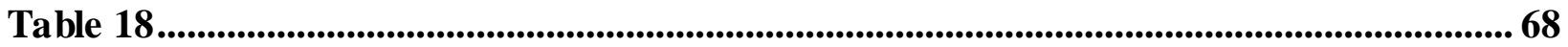

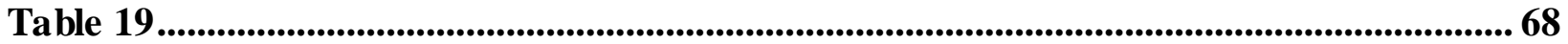

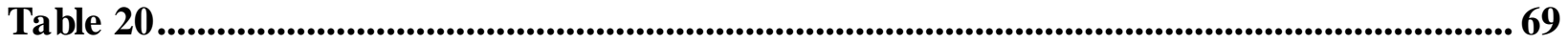

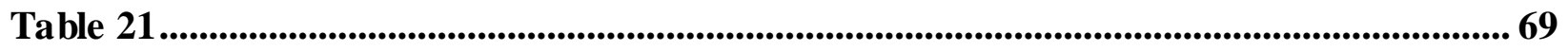

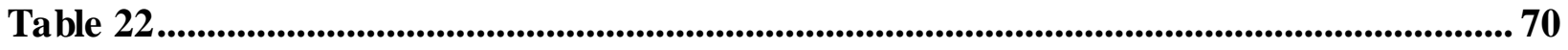

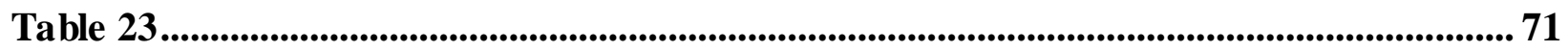

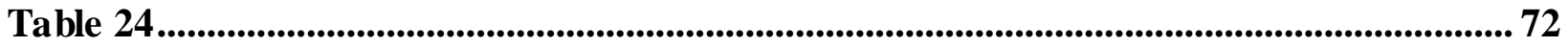

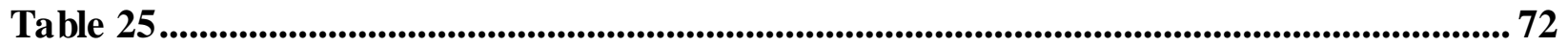

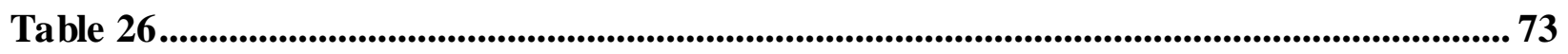

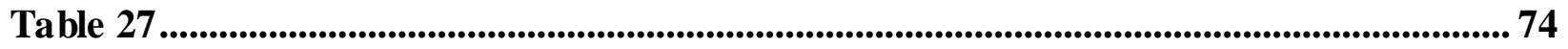




\begin{abstract}
Data derived from universal screening procedures are increasingly utilized by schools to identify and provide additional supports to students at-risk of behavioral and emotional concerns. As screening has the potential to be resource intensive, effort has been placed on the development of efficient screening procedures, namely brief behavior rating scales. This study utilized classical test theory and generalizability theory to examine the extent to which differences among students, raters, occasions, and screening measures affect the meaningfulness of data derived from universal screening procedures. Teacher pairs from three middle school classrooms completed two brief behavior rating scales during fall and spring screening administrations for all students in their respective classrooms. Correlation coefficients examining interrater reliability, test-retest reliability, and concurrent validity were generally strong. Generalizability analyses indicated that the majority of variance in teacher ratings were attributable to student differences across all score comparisons, but differences between teacher ratings for particular students accounted for relatively large percentages of error variance among student behavior ratings. Although decision studies showed that increasing the number of screening occasions resulted in more generalizable data, the impact of increasing the number of raters resulted in more efficient screening procedures.
\end{abstract}




\section{Chapter I: Introduction}

Universal screening for behavioral and emotional risk (BER) is a proactive strategy for identifying students who may develop future mental health problems and serves as a primary method of data gathering within many preventative school-based service delivery models (Eklund \& Dowdy, 2014; Kamphaus, 2013). A primary goal of universal screening is to identify all individuals within a population that are at risk for behavioral and emotional difficulties. As a result, screening measures must be highly efficient, conserve resources, and provide useful data in student decision-making processes (Bruhn, Woods-Groves, \& Huddle, 2013; Glover \& Albers, 2007; Lane, Menzies, Oakes, \& Kalberg, 2012). The potential costs associated with such a widely administered assessment have called into question the feasibility of universal screening in school settings (Kamphaus, 2013). Although several types of screening methods exist, brief behavior rating scales (BBRS) have been developed to increase the feasibility of universal screening in schools through a reduction in the work hours needed to screen an entire classroom (Kilgus, Sims, von der Embse, \& Riley-Tillman, 2014). As data generated by BBRS are increasingly used by school professionals to inform the provision of behavioral supports, it is important that these tools are psychometrically sound, producing stable and accurate scores.

Research examining the measurement error in BBRS has done so almost exclusively through traditional reliability coefficients founded in classical test theory (CTT). CTT is helpful because it provides useful information regarding the stability and precision of scores used in universal screening procedures. However, examining measurement error in CTT is limiting for two primary reasons: (1) all error in CTT is treated as random, which may not be true as largescale measurement procedures (e.g., universal screening) are used in applied settings (e.g., schools); and (2) although error may stem from multiple components of the measuring procedure 
(e.g., rater, setting, instrument), all error in CTT is represented by a single error term (Briesch, Swaminathan, Welsh, \& Chafouleas, 2015). As a result, reliability coefficients that attribute error to the different screening occasions (e.g., test-retest reliability) or the choice of rater (e.g., inter-rater reliability) are unable to simultaneously account for a variety of factors (e.g., rater, occasion, method) that may affect a score.

Current research on universal screening has led to the development of several measures that are contextually appropriate, technically adequate, and highly usable (Glover \& Albers, 2007; Kamphaus, 2013). However, more research is needed to understand the contribution of important components (e.g., rater selection, occasion of measurement, instrument choice) involved in universal screening procedures. The primary focus of the current study, therefore, is to examine the factors contributing to measurement error in universal screening for BER using generalizability theory ( $\mathrm{G}$ Theory). $\mathrm{G}$ theory provides several advantages over traditional reliability analyses. Investigation of these factors provides information that may be used to (1) examine the meaningfulness of interpretations drawn from universal screening data, and (2) strengthen subsequent measurement tools and procedures. The current study seeks to address the following questions:

1. What is the test-retest, inter-rater reliability, and concurrent validity of brief behavior rating scales?

2. What percentage of variance in data derived from screening scores is attributable to differences between students, teachers, occasions, measures, and/or the interactions between these factors?

3. How does altering the number of raters and occasions affect the generalizability of universal screening scores? 


\section{Chapter II: Literature Review}

Approximately one third of children and adolescents in the United States will meet diagnostic criteria for a mental health disorder by age 18 (Merikangas, et al., 2010; Miller et al, 2015). Mental health difficulties are associated with a variety of negative consequences, including poor academic achievement, absenteeism, impaired relationships, substance abuse, involvement in the juvenile justice system, and suicide (Chin, Dowdy, \& Quirk, 2013; Dvorsky, Girio-Herrera, Owens, 2014; Kern, Hilt-Panahon, \& Mukherjee, 2013). Furthermore, the schoolbased tragedy at Sandy Hook in Newton, Connecticut serves as a somber and extreme reminder of the importance of ensuring mental health services are provided to those who may need them (Cowan \& Vaillancourt, 2013). Yet, fewer than one-third of youth with mental health concerns receive any treatment or support (Merikangas et al., 2010). Schools may play an important role in promoting the mental health of students through early identification strategies that can link students to necessary supports (Miller et al., 2014).

Schools are increasingly concerned with the provision of mental health treatment, as academic accountability (e.g., No Child Left Behind Act, 2001) and special education (e.g., Individuals with Disabilities Education Improvement Act, 2004) legislation requires schools to address the social, emotional, and behavioral needs of students. Furthermore, research continues to demonstrate that social, emotional, and behavioral difficulties are linked to important academic outcomes. For example, $75 \%$ and $97 \%$ of students with mental health difficulties achieved below grade level in reading and math, respectively (Bradley, Doolittle, \& Bartolotta, 2008). As schools have the ability to reach large numbers of children and adolescents, they are strategically placed to address the identification and treatment needs of youth with mental health 
difficulties (Levitt, Saka, Hunter Romanelli, \& Hoagwood, 2007). However, additional research is needed to determine effective strategies for reaching at-risk youth in schools.

\section{Identifying Students At-risk of Behavioral and Emotional Concerns}

Schools have traditionally relied upon a referral-based method of identification, in which school personnel refer a student for help, support, and/or evaluation (Menzies \& Lane, 2012; Renshaw et al., 2009). However, there are two main limitations when teacher referral is used to identify students. First, teacher referral best identifies students at-risk for school failure due to their disruptive behaviors (Kamphaus et al., 2010). For example, oppositional, hyperactive, or aggressive behavior concerns are more likely to be detected and referred by teachers than internalizing concerns such as depression or anxiety among students (Cook, Volpe, \& Livanis, 2010; Kamphaus, Dowdy, Kim, \& Chin, 2013). This is problematic as research demonstrates the negative influence of depression and anxiety on academic (e.g., school completion, lower academic achievement, attendance) and non-academic (e.g., underemployment, substance use, suicide) outcomes (Bruhn et al., 2013; Chin et al., 2013).

Second, teacher referral may preclude students from treatment delivered during the early stages of a disorder, when symptoms may be more amendable to intervention and exert less of an impact on the classroom environment (Albers, Glover, \& Kratochwill, 2007; Dowdy et al., 2014). Without early identification, the course of a disorder may progress from a relatively minor ailment during the prodromal or beginning stages, into a more significant condition impairing major life activities and functioning. Therefore, treatment options under referral-based methods must wait for significant impairment. The preponderance of a "wait to fail" model of identification currently present in schools (Albers et al, 2007) suggests sole reliance on referral- 
based identification methods may not only contribute to the treatment gap, but also lead to less than optimal treatment options once a need has been identified.

In response to the limitations of referral-based methods, schools are increasingly embracing multi-tiered systems of support (MTSS) to identify and support students' mental health needs. Departing from traditional methods of identification, MTSS rely on the systematic collection and analyses of data to prevent the development of disorders and identify students in need of further support (Jimerson, Burns, \& VanDerHeyden, 2015; Kilgus, Reinke, \& Jimerson, 2015). Typically, MTSS emphasis on data allows the treatment of students to be conceptualized within three tiers of increasingly intensive mental health services, including universal (Tier 1), selected (Tier 2), and indicated (Tier 3) levels os support (Miller et al, 2015). All students at the Tier 1 or universal level receive the same mental health supports. A prime example of universal supports are school-wide positive behavior interventions and supports (PBIS), a framework in which appropriate behavioral expectations are explicitly taught to students and a consistent system to reward good behavior and correct negative behavior is implemented (Jimerson et al, 2015; Sugai \& Horner, 2009).

Approximately $20 \%$ of students in schools utilizing MTSS may require additional schoolbased mental health supports beyond the universal level. Tier 2 services are considered more targeted and individualized interventions, often provided in small groups (Lane et al., 2012; Severson et al., 2007). Examples of Tier 2 interventions include Check-in/Check-out (Hawken \& Horner, 2003) and group-based skill instruction emphasizing the development of key social skills (McIntosh et al., 2014).

A few students may require additional supports beyond those provided at Tier 2. Tier 3, or intensive and individualized interventions, are often provided to students who demonstrate 
well-developed and severe symptoms. These services may include community wrap-around services, individual therapy, individualized education plans, and services provided in a selfcontained classroom.

An important component of MTSS are how students are identified for services. Founded in the public health approach, MTSS uses surveillance strategies in order to identify students who might be at-risk of developing future behavioral concerns (Herman, Riley-Tillman, \& Reinke, 2012). Surveillance serves several purposes within these public health models, including proactive identification of risk or impairment in order to provide earlier treatment, reducing the spread of disease, and linking types or levels of intervention to the monitored population (DiPerna et al., 2013). Although surveillance traditionally concerns the prevalence and incidence of somatic disease, MTSS extends the concept of surveillance to school-based mental health systems by using thoughtfully collected data (Miller et al., 2015). When the goal is to increase access to school-based services and address student's behavioral and emotional concerns, surveillance data can be gathered through universal screening methods. As the basis for treatment decisions in MTSS, universal screening is of paramount importance for the overall efficacy of MTSS models.

In practice, universal screening for BER is somewhat analogous to vision and hearing screenings that are widely administered in the schools, whereby screening data is used to, "detect students who are at risk and may need further diagnostic assessment or who could benefit from targeted intervention" (Bruhn, et al., 2014, p. 612). Although universal screening comprises a heterogeneous group of measurement procedures and tools, the defining feature is assessment of all individuals belonging to a population (e.g., all students within a classroom, school, or district) to detect the presence of a variable of interest (Kamphaus, 2013). Screening for behavioral and 
emotional risk is important to schools because it offers an opportunity to identify behavior predictive of future mental health disorders (Kilgus, Reinke, \& Jimerson, 2015). This early identification data can then be used to provide follow-up treatment, therefore diminishing the severity of a disorder, shortening its duration, and potentially resulting in less expensive treatment options (Forness, Freeman, Paprelle, Kauffman \& Walker, 2012).

Whether universal screening is used within a MTSS framework or as a stand alone assessment practice, universal screening procedures confer schools three main benefits over traditional models of identification (Dvorsky et al., 2013; Kilgus \& Eklund, 2016). First, universal screening for BER examines all students within a school or classroom which ensures that all students have access to services. This includes students at-risk for an internalizing disorder who may be overlooked via traditional identification methods dependent upon externalizing behavioral concerns (Bruhn, et al., 2014; Levitt et al., 2007). Second, universal screening data can be used "to provide a baseline against which future student monitoring can be benchmarked" (Dvorsky et al, 2013, p. 298). This benchmark allows schools to monitor student's behavioral functioning over time. This may provide useful information regarding critical periods of development (e.g., adolescence), transitions (e.g., middle to high school), and when a student may experience a predisposing factor to developing BER. Third, universal screening facilitates early interventions through proactive early identification. Intervention applied early tends to be less intensive, more economical (see O'Connell, [2009] for a review), and results in a beneficial impact that is important for positive student academic and behavioral outcomes (Dowdy et al., 2014; Herman et al., 2012).

Despite these potential benefits, only $12.5 \%$ of schools currently screen students for emotional and behavioral problems (Bruhn et al., 2014). Although this represents an increase 
from a 2005 study that found $2 \%$ of schools had adopted behavioral screening procedures

(Romer \& McIntosh, 2005), this number is far below rates for academic screening measures as $85 \%$ of schools' report using academic screening or formative assessment data in student databased academic decision making procedures.

This lack of adoption may be the result of community and educator attitudes regarding the role in treating mental health challenges, fear about the possibility of incorrectly labeling students with a stigmatizing diagnosis, concerns of overwhelming finite school resources, a general lack of school resources, and accountability efforts stressing academic achievement over the social, emotional, and behavioral development of students (Cook, Volpe, \& Livanis, 2010; Forman, Jofen, \& Lubin, 2013). However, this lack of adoption may also reflect the need for screening tools that demonstrate (1) contextual appropriateness (e.g., consideration of service delivery needs, alignment with constructs of interest, adequacy of norms); (2) usability (e.g., feasibility, cost, ease of use); and (3) technical adequacy (e.g., validity and reliability of evidence; Glover \& Albers, 2007).

\section{Universal Screening Procedures and Tools}

According to Kamphaus and colleagues (2013), requests for BER screening in schools have been documented for decades (e.g., Reynolds, 1979), with measures designed intently for use in the school context since the 1970's (e.g., Cowen et al., 1973). Severson and colleagues (2007) identified four general categories of universal screening procedures and measurement tools: (a) multiple gating procedures, (b) teacher nomination of problem students followed by successive assessment, (c) the use of office discipline referrals and similar permanent products, and (d) teacher evaluation using behavioral rating scales. Each method possesses its strengths 
and limitations and there may not be a correct answer pertaining to screening tool choice (Cook, Volpe, \& Livanis, 2010).

Multiple gating procedures. Multiple gating procedures are characterized by the use of multiple assessments delivered in a series of prescribed steps, called gates (Miller et al., 2015).

To save valuable resources, teachers assess every student within their classroom using a highly efficient screening tool (e.g., teacher nomination, behavior rating scale) at the first gate.

Students demonstrating elevated risk are then administered a more comprehensive assessment to identify areas of concern and to rule out false positives (discussed in detail in the next section).

The Systematic Screening for Behavior Disorders (SSBD; Walker \& Severson, 1990) is one example of a multiple gating procedure whereby all students in a classroom, grade, or school are screened for BER, with at-risk students receiving additional assessment to determine their level of need. Similarly, the Behavioral and Emotional Screening System (BESS; Kamphaus \& Reynolds, 2007) has been used as a first gate screener due to it's brevity (i.e., 27 items). For example, once an entire class is screened using the BESS, a second gate assessment, such as the Behavior Assessment Scale for Children, Second Edition (BASC-2; Kamphaus \& Reynolds, 2007), would be completed by a teacher, student, or parent. A benefit of using a second gate measure such as the BASC-2, is that it provides additional information regarding the type of behavioral, emotional, adaptive, or social difficulties a student may be experiencing.

Multiple gating procedures can also rule out two types of errors when using universal screening measures for identification purposes: false positives and false negatives (Lane, Oakes, \& Menzies, 2010). A false negative occurs when a student is not identified through screening procedures, when in fact they demonstrate BER. False negatives can lead to students being overlooked, who do, in fact, demonstrate behavioral concerns. To control for false negatives, 
multiple gating procedures aim to cast a wide net by identifying as many students as possible, at the potential cost of creating too many false positives. A false positive occurs when a student is identified as having BER, when in fact they do not. A consequence of a false positive could be incorrectly identifying a student as demonstrating risk or inefficient use of school resources, resulting from treating those students who do not need it, incorrectly alarming parents, and the stigma associated with a diagnostic label. Therefore, a benefit of a second gate assessment is to control for false negatives, as they provide more information about the treatment of those who actually exhibit risk, and rule out incorrect cases (Kamphaus, 2013; Levitt et al., 2007). It is important to note that both of these types of error are directly related to the cut-off or criterion (e.g., a score above the $70^{\text {th }}$ percentile, two or more office discipline referrals) chosen to operationalize an unacceptable level of BER.

The usefulness of adding a second gate screener may not always be superior to administering a single initial measure. For example, the Student Risk Screening Scale (SRSS; Drummond, 1994) is a seven-item scale that was found to be similar in classification accuracy to the three-stage process used with the SSBD, discussed previously (Ennis et al., 2012). However, the SRSS failed to identify students with internalizing difficulties due to its focus on externalizing behaviors and academic concerns. Another drawback to multiple gating procedures includes the increased use of teacher time and school resources (Levitt, et al., 2007).

Teacher nomination. Teacher nomination "relies on teachers to systematically identify which students display clearly described symptoms of mental health problems" (Cunningham \& Suldo, 2014. p. 238) and is often utilized within the larger model of multiple gating procedures. For example, a classroom teacher may be asked to rank order students' demonstrating 
internalizing behavioral concerns and those students demonstrating externalizing behavioral concerns, after being provided an operational definition of these behaviors.

Teacher nomination is appealing because of its efficiency, relatively low cost, and face validity (i.e., the idea that teachers are capable of correctly identifying at-risk students because of their daily student contact; Cunningham \& Suldo, 2014). Although teacher nomination is time efficient and inexpensive, it has been shown to be less effective for identifying the full range of difficulties that may lead to the development of a mental health disorder. Compared to other screening tools (i.e., rating scales), teacher nomination procedures have been found to result in fewer students being identified for services because of a primary focus on more disruptive behavioral concerns (Dowdy, Doane, Eklund, \& Dever, 2013). For example, a teacher nomination procedure was found to identify five times as many students with externalizing difficulties than those students with depression and anxiety (Soles, Bloom, Heath, \& Karagiannakis, 2008).

Office discipline referrals. Office disciplinary referrals (ODR) are school archival records containing information regarding the location (e.g., classroom, bus) and type of problematic behavior (e.g., aggression, disrespect) that resulted in a student rule infraction (McIntosh, Spaulding, \& Frank, 2010; Sugai \& Horner, 2006). Data generated by ODR records can provide schools beneficial information regarding the rate of problematic behaviors, school climate, and student engagement (McIntosh, Reinke, \& Herman, 2010). ODRs can be specifically used to screen for BER by using higher rates of ODRs to identify at-risk students. Typically, students with two or more ODRs are considered at-risk of future behavioral concerns (Burns et al., 2014). ODRs have been found to be efficient, requiring little teacher time and school resources and many schools already collect this information (Cunningham \& Suldo, 
2008). The number of ODRs has shown been shown to be predictive of behavior disorders, delinquency, dropout occurrence, substance use, and academic underachievement (Predy, McIntosh, \& Frank, 2014).

However, ODRs appear to demonstrate a few limitations as significant negative correlations between internalizing disorders and ODRs have been documented (McIntosh et al, 2009). As internalizing difficulties have a different behavioral manifestation compared to externalizing difficulties, students with internalizing problems are less likely to disrupt classroom and school routines enough to warrant an ODR. As a result, a likely consequence of exclusive reliance on ODRs for the purposes of screening is the under-identification of some students (e.g., those with internalizing disorders) who may benefit from services (Caldarella et al., 2009).

Brief behavior rating scales. The use of ratings scales has been found to structure teachers' qualitative perceptions to better align with the construct of BER (Eklund et al., 2009). Instead of using traditional rating scales, such as the Achenbach Child Behavior Checklist (ASEBA, Achenbach \& Rescorla, 2001) or the BASC-2 (Reynolds \& Kamphaus, 2004), which often include upwards of 100 items, schools have turned to more efficient measures, which require much less teacher time. These brief behavior rating scales (BBRS) are characterized by (1) the use of teachers as informants to rate students' frequencies of behaviors; (2) a small number of items, ensuring that they can be completed in a timely manner; and (3) assessment of a small number of latent variables that are highly relevant to social and academic success, including externalizing behavior, internalizing behavior, attention problems, social competencies, and academic competencies (Kilgus et al., 2014).

When using BBRS to identify BER, students who show above average frequencies of problematic behavior, or below average frequencies of protective behaviors are considered at- 
risk. Examples of these measures include the Student Risk Screening Scale (SRSS; Drummond, 1994) and the Strengths and Difficulties Questionnaire (SDQ; Goodman, 1997). BBRS correlate with traditional rating scales, ODRs, grades, and school absences (Dowdy et al., 2013; Eklund et al., 2009; Eklund et al., 2014). However, BBRS may also be associated with several problems including error variance and response bias (Whitcomb \& Merrell, 2012). Response bias results from the way a rater approaches the task of completing a rating scale. For example, some raters may refrain from giving a student an extreme score on a Likert scale, even though it may be accurate an accurate descriptor.

\section{Validity and Reliability in Universal Screening}

As the scores assigned by universal screening are used to determine the need for interventions and guide services within MTSS and surveillance frameworks, it is important that they provide psychometrically sound and meaningful data. Two ways to ensure the dependability and consistency of this data is through the use of the reliability and validity evidence demonstrated by universal screening results (The Standards; American Educational Research Association, American Psychological Association, \& National Council on Measurement in Education, 1999). Validity represents "the degree to which evidence and theory support the interpretations of test scores entailed by proposed uses of tests" (The Standards, 1999, p. 9). In universal screening measure for BER, validity is concerned with the interpretations that can be drawn from the data regarding the trait of BER. For example, a screener could demonstrate validity by being able to predict future difficulties that stem from BER. Reliability is the "stability, consistency, and dependability of scores for individuals on the traits, characteristics, or behavior being assessed" (Mitchell, 1979, p. 376). While both concepts indicate the extent to which data is meaningful for a specific purpose, issues concerning validity 
must be placed on the backburner, as accuracy must be established by first measuring procedure (Cone, 1977).

\section{Classical Test Theory}

A core assumption of classical test theory (CTT) is that an observed score $(X)$ is comprised of two theoretical components: the true score $(T)$ and error score $(E$; Christ \& Nelson, 2013). Typically, researchers think of the error score as a nuisance variable that negatively influences a measure's ability to assess the true score, which is the "true" value of the construct being measured (Ree \& Carretta, 2006). In the current study, BER is the trait of interest. Neither the true score nor the error score can be observed directly, rather, they are inferred across parallel measurements. Differences between these scores indicate the degree of error in a measure, as the true score is considered a stable and fixed quantity. One way to conceptualize error is through use of a reliability coefficient. Although several types of reliability coefficients exist, each is defined as the ratio of true score variance to total observed variance (Crocker \& Algina, 2006). Reliability coefficients can assess the stability of screening scores through occasions (e.g., test-retest), across rating scales (e.g., concurrent validity and between raters (e.g., inter-rater). The higher the degree of score similarity, the more reliable a measure is thought to be, as traits are considered to be stable. Traditional reliability coefficients are often presented and interpreted separately, as they are only capable of attributing error to a single source (Cone, 1977).

There are two limitations regarding the conceptualization and treatment of measurement error in CTT. First, CTT considers all error variance random. Error is considered random when it is thought to influence all conditions of measurement equally and indiscriminately (Aronson, Ellsworth, Carlsmith, \& Gonzalez, 1990). If error is random, the screening results obtained from 
two parallel measurements within one classroom will affect the variation in scores between two classrooms. This assumption is reasonable when conducting measurements in highly controlled environments (Briesch et al., 2014). However, when conducting measurement procedures that involve many measurement components (e.g., universal screening) in applied settings (e.g., schools), it is plausible that systematic error could be affecting scores. Systematic error is much more insidious, as it tends to differentially influence the scores in one condition. For example, scores obtained from one classroom teacher's ratings of the behavior of one student may be lower than the scores of another classroom teacher's behavior rating of the same student. These differences in ratings due to systemic variance resulting from differences between teachers' perceptions of student behavior or class environments. The implications for systematic error in screening are many, but in this example, the differences between teachers may lead to more or less students receiving the support they need.

The second limitation of CTT relates to the single error term that represents all error. CTT purports to emphasize certain kinds of error, depending on the type of reliability coefficient calculated. For example, a test-retest reliability coefficient assesses different occasions, but error may emit from the choice of rater (Volpe et al, 2011). The use of a single error term "does not mean that there is necessarily only one source of error [affecting a score], however, within a single application of CTT, all sources of error are confounded in one E term” (Brennan, 2011, p.7). While reliability coefficients are used to attribute error to different occasions of measurement (e.g., test-retest reliability) or the choice of rater (e.g., inter-rater reliability), these scores are unable to simultaneously examine the impact of the multiple factors (e.g., rater, occasion, method) that may contribute systematic error in a score. In the previous paragraph, two conditions of measurement could potentially cause different scores between two similar 
conditions of measurement: the teachers' rating of the student, or true differences between classrooms. When this is assessed via a test-retest reliability coefficient, all error is attributed to raters when in fact differences between raters or classroom differences may be the primary contributing factors to the error observed in a single coefficient.

A specific measure is not reliable; rather the data generated under the specific measurement conditions comprised of specific people at specific times shows evidence of reliability (Briesch et al, 2014; Ree \& Carretta, 2006). Thus, it is important to examine the conditions affecting the reliability of a score. For BBRS these may include temporal variance (e.g., inconsistencies in behavior ratings over time), setting variance (e.g., differences between settings of behavior), instrument variance (e.g., differences between measures assessing the same construct), and source variance (e.g., differences between raters; Merrell \& Whitcomb, 2012). The contribution of these sources to error and the reliability of data generated through a typical school-based universal screening procedure examining behavioral and emotional risk have yet to be examined simultaneously.

\section{Generalizability Theory}

Generalizability theory (GT) provides a potential alternate means of assessing and quantifying measurement error in applied settings (Brennan, 2001; Shavelson, Webb, \& Rowley, 1989). GT serves as a powerful analytic method to examine the measurement procedure as it exists in applied settings (Cronbach, Glaser, Nanda, \& Rajaratnam, 1972). GT was originally conceptualized as a liberalization of CTT, and blurs the lines between validity and reliability (Cone, 1977). This section provides an overview of generalizability theory, relevant theoretical underpinnings, and their application to universal screening for BER. 
Briesch and colleagues (in press) have identified three benefits of GT that are relevant to school-based universal screening: (1) GT provides a method of examining multiple sources of error variance affecting measurement simultaneously, through variance component analyses; (2) These variance components allow for the calculation of generalizability and dependability coefficients; and (3) These variance components can be used to conduct a decision study. Generalizability theory includes many important concepts that apply to universal screening measures and procedures, including the treatment of scores and measurement, partitioning variance, identifying facets or factors, and the calculation of generalizability and dependability coefficients.

Scores and measurement. The purpose of measurement is to draw general conclusions from a score (Sireci, 1998; Cronbach et al., 1972). In universal screening, the researcher may wish to say, "Johnny's score was X", not, "Johnny's score was X as rated by Mr. Davis on October $31^{\text {st }}$ in math class using screener Y." Operating under this assumption in the current study, schools intended use of screening data is to draw general conclusions about Johnny's level of risk in order to ensure that he will receive services. Likewise, the goal of using GT is to determine how well the score obtained using a specific measure as rated by a specific rater is representative (i.e., generalizable) to what would be considered typical across all possible raters, all possible test occasions, and all possible screening measures to generate the most useful information. To accomplish this task, GT posits that data must be gathered using a measurement procedure that makes it possible to generalize results across all important conditions of the measurement procedure (e.g., occasion, rater, and measure; Wright \& Piersel, 1992).

Cronbach and colleagues (1972) emphasized that the measurement procedure is the basis for drawing inferences or making decisions. This is in contrast to CTT, which treats error as 
bound to a specific test. Although the measurement procedure itself may be comprised of specific components (e.g., identifying student risk based on results obtained from a specific rater at a certain time, using a selected measure), these components are somewhat arbitrary, especially if a screening researcher decides that the choices of rater, instrument, or assessment occasion could have easily been substituted for comparable alternatives and still result in data that is equally usable and adequate for the assessment. The limiting factor is the researchers' conceptualization of what components of the measurement procedure would still generate an acceptable, useful, and meaningful score for use in the same decision. When components of a measurement procedure are viewed in this manner, there are many ways of assessing a single construct of interest that are equally as useful (Briesch et al., 2014). For example, the choice of using a fifth period teacher or a second period teacher from a particular high school to obtain ratings of student behavior may be viewed as equally acceptable. Thus, the specific components of a measurement procedure are drawn from a large pool of acceptable observations, defined as the conditions that would yield acceptable data for use in decision making.

When examining GT, these components of a measurement procedure that produce acceptable observations are specified as facets (e.g., raters and method). The ideal data for decisions would include a person's average score across all acceptable observations, also known as the "universe score". Similar to the concept of a true score in CTT, the universe score in GT serves as the entity in which we wish to draw inferences. GT examines the accuracy of generalizations. For example, many children and adolescents are at-risk for, or are currently experiencing mental health difficulties. Brief behavior rating scales are used within MTSS models to identify which students are at-risk of future concerns. As such, these scales should 
generate meaningful data regarding students' level of risk by ensuring that data is relatively free of error. However, most research to date has examined the psychometric properties of BBRS from a CTT perspective. The conceptualization of measurement error under CTT has failed to examine the complex nature of screening within school settings, as measurement error is considered random and is collapsed into a single, undifferentiated source. Although this traditional approach provides information about the precision of a measurement in schools, the use of teacher ratings of student behavior in school constitutes a significant departure from the level of strict control for measurement error to be considered fully random. Therefore, it is entirely plausible that the nature of universal screening procedures is not being optimally examined through CTT analyses. Specifically, it is likely that measurement error in universal screening is (1) systematic and (2) that teacher selection, measurement choice, and screening occasion differentially affect the meaningfulness of data. The goal of GT, then, would be to examine the accuracy of generalizing an observed score across all possible measurement conditions (e.g., raters, occasions, methods, etc.), and to examine if the results are acceptable and generate meaningful data about students' BER.

Assessing variance with generalizability theory. The amount of variance attributable to a facet is first assessed with a generalizability study ( $G$ study). The goal of a G study is to concurrently examine the percentage of variance attributable to each of the variance components. During a G study, variance components are obtained from two instances of a facet, and are used to calculate variance components for each facet. For example, a G study design may include two raters using two screening measures, as this provides an examination of the variance components of two facets (e.g., rater and instrument). GT quantifies multiple sources of error variance with a repeated-measures factorial ANOVA. Three classes of variance are calculated during a G study: 
(1) the object of measurement, (2) facets of generalization, and (3) the interactions between these facets (Bloch \& Norman, 2012).

It is important to note that multiple kinds of facets can be simultaneously represented in a G-study, including fixed or random facets. A fixed facet occurs when a measurement procedure calls for a specific instance that is not exchangeable, whereas a random facet occurs if a researcher considers instances exchangeable. In screening procedures, an occasion may be considered a random facet, as the specific time period or date in which students are assessed is variable and the screening administrator considers the data generated on these days to be just as useful. However, the choice of instrument may be considered a fixed facet, if for example, a school district has only purchased a single assessment measure.

Facets may also be crossed or nested. A crossed facet is one in which all levels of the facet are present across all levels of another facet. In universal screening procedures, an example of crossed facet would be having every student $(p)$ in a school rated by every teacher (r). However, this is not realistic for universal screening procedures, as it would be impractical and unreasonable for each teacher to rate every student in a school. Thus, screening typically involves nesting. A nested facet occurs when teachers only rate the students in their respective classrooms. Thus, teachers (raters) are nested within classrooms. The distinction between nested and crossed variables is important, as nesting makes it impossible to partition the variance from the variable that it is nested within and the facet we are interested in examining. Thus, this confounded variance means that the variance in nesting variables is summed together (e.g., the variance for teacher and student). This is viewed as acceptable because of the high degree of inter-rater reliability. 
Sources of measurement variance. The variance attributable to the object of measurement is the "true variance"; stemming from the real individual differences that exist between people on any given trait. In a G study examining universal screening for BER in schools, a student's risk score would be considered the object of measurement (Brennan 2001; Shavelson \& Webb, 1991). This variance is considered "true" because it represents the differences that are expected to occur between individuals for a given trait, in this case, BER (Wright \& Piersel, 1992). In screening the true variance is the difference between students' risk scores. In a GT model using typical GT notation, this variance is often referred to as person variance and represented by a $p$. It is considered desirable to have most of the variance attributable to person differences. Variance components stemming from the conditions of measurement are referred to as the facets of generalization in GT (Bloch \& Norman, 2012). The four facets relevant to universal screening that are considered error variance, that is, the variance not attributable to individual differences of risk, are rater $(r)$, occasion $(o)$, classroom $(c)$, and method $(m)$.

Rater. Many universal screening procedures rely on teachers to generate meaningful data about students' levels of risk. The facet of rater is similar to inter-rater reliability, which assesses if the data generated between raters significantly differ (Cone, 1977). Rater variance can be used to examine the scores of one teacher compared to that of another teacher. If meaningful differences exist between teacher scores, then the percentage of variance attributable to the rater would be relatively large in comparison to variance attributable to person differences. The practical implication of rater variance has to do with rater selection in universal screening. If different teachers rate the same student differently, then our confidence that the risk score is actually representing BER is lessened, as differences in scores may be more representative of 
how teachers differentially approach the task of rating. As a result of rater variance, the choice and type of rater may yield less or more dependable data regarding students' levels of BER (Cone, 1977).

Occasion. Within universal screening procedures, the facet of occasion examines if BER varies significantly at different points in time. As screening measures are often conducted at multiple time points (e.g., fall, winter, spring) throughout the year to adequately assess the presence of BER (Kamphaus et al., 2012), it is important to assess variance or the error in measurement due to the differences between occasions. Occasion variance, then, is similar to test-retest reliability, by examining differences between the scores obtained at different time points (Briesch et al., 2014). A large percentage of variance stemming from occasion would indicate that the scores obtained at one point in time are not generalizable to scores obtained at a different time point (Cone, 1977). Analyzing this variance would provide beneficial data as to the stability of BER scores across time. If BER is a trait, it is reasonable to expect that risk level, in the absence of treatment, should not fluctuate.

Method. The facet of method can be used to examine the extent to which the scores generated by one screening measure are comparable with those generated by another. This concept is similar to concurrent validity within CTT (Briesch et al., 2014), as the instrument variance results from differences in two measures assessing the same construct. If a small amount of variance is observed in results from two different screening measures, then the choice of screener may be less meaningful. For example, if concurrent use of a longer and shorter screener result in little variance, then screening procedures could be made more efficient by utilizing the shorter measure when time constraints are a consideration in applied settings. 
Facet interactions. GT also permits the examination of interactions between facets. Although interaction effects are harder to verbalize, they may provide important information regarding how facets interact with one another. The interaction between the facets of person and rater are of particular importance as certain scores for the same person may differ significantly, indicating the presence of rater bias (Briesch et al., 2014). In other words, rater and student interaction variance is attributable to the unique perceptions raters have of particular targets. Thus, a large portion of variance due to interaction between the rater and person would indicate that specific raters are systematically rating specific students differently (Bergeron, et al., 2008). Rater bias can occur for a number of reasons, including halo and leniency effects (Merrill \& Whitcomb, 2012).

Dependability and generalizability coefficients. The ability of a measurement procedure to generate scores capable of drawing general conclusions from the universe of acceptable observations can be summarized by a generalizability and dependability coefficient (Shavelson \& Webb, 1991; Suen \& Pui-Wa, 2007). Generalizability coefficients are conceptually similar to the concept of reliability in CTT (Shavelson, Webb, \& Rowley, 1989). Unlike traditional reliability coefficients, which only assess relative decisions (e.g., relative ranking of individuals), dependability coefficients can be estimated for absolute decisions (Briesch et al., in press; Chafouleas, Kilgus, \& Wallach, 2010). This is relevant to universal screening as the use of a cut score for determining BER is an example of absolute decisionmaking.

Decision (D) studies allow the researcher to examine how increasing or decreasing the sample size facet changes the dependability and generalizability coefficient estimates (Brennan, 2001; Cronbach et al, 1972). These can be conducted on various facets and are similar to the 
Spearman-Brown prophecy formula, which is used to determine how many items may be needed to obtain a reliable estimate of a trait (Cronbach et al, 1972). D studies have been employed to assess how dependability changes as a function of the length of probes (e.g., Christ, JohnsonGros, \& Hintze, 2005; Volpe et al., 2011) or the number of probes administered (e.g., Poncy, Skinner, \& Axtell, 2005). Thus, a universal screening D study could examine the effect of increasing the number of occasions or ratings on the generalizability of the overall procedure (Webb, Shavelson, \& Haertel, 2006). Analyses could also attempt to maximize efficiency through the alteration of variance components. For example, decreasing the number of occasions screening measures are administered (e.g., once a year) while increasing the number of raters (e.g., self reports, teacher ratings) might produce more efficient universal screening procedures.

\section{Generalizability Theory with Universal Screening for BER}

Briesch and colleagues (in press) identified 45 published studies that used generalizability theory in academic settings from 1972 to 2015, including academic $(\mathrm{N}=34)$ and behavioral $(\mathrm{N}=11)$ measurement procedures. From the relatively few studies examining behavioral assessment procedures, most examined full-length behavior rating scales (e.g., Bergeron, Floyd, McCormack, \& Farmer, 2008; Wright \& Perciel, 1992) and only one study examined the applicability of GT using brief behavior rating scales (Volpe, Briesch, \& Gadow, 2011). To date, no studies have used generalizability theory to examine universal screening procedures.

Generalizability theory and behavior rating scales. Wright and Piersel (1992) examined the Burks Behavior Rating Scale, a 110-item behavior rating scale assessing a variety of behavior problems across 19 subscales (Burks, 1977). This study included an elementary school sample comprised of 34 boys and 19 girls in first through sixth grades who had been 
referred for learning or behavior problems. Reliability coefficients and G theory were used to examine the variance associated with scores (person), content (items), teachers (rater), and setting for each of the 19 individual subscales. This study found large amounts of unspecified error variance in the majority of subscales, which can be caused by a lack of model specificity (Brennan, 2001). Furthermore, only seven of the nineteen subscales contributed more than $40 \%$ the total variance to the facet of person. Thus, the scores representing the trait were likely impacted by other aspects of the measurement process. However, due to the amount of variance unspecified by any facet included in this model, it is impossible to parcel out how the measurement procedure failed to adequately examine the purported trait assessed.

Bergeron and colleagues (2008) examined the percentage of variance attributable to students (person), teacher (raters), instruments (method), and the different administration dates (occasion) using the externalizing composites of the Teacher Report Form of the BASC-2 (Reynolds \& Kamphaus, 2004) and the Achenbach System of Empirically Based Assessment, Teacher's Report Form (ASEBA TRF; Achenbach \& Rescorla, 2001). Six teacher pairs rated each student in the shared classroom to produce a total rating of 61 elementary school students. Teacher pairs rated each student twice, three weeks apart on each measure. This resulted in a partially nested design using 6 teachers and 61 students nested in six classrooms, fully crossed with two occasions and two instruments. The results indicated that the students within each classroom accounted for the largest percentage (67.7\%) of the total observed variance in BASC2 externalizing composite scores. $11.5 \%$ of the total variance was not attributable to any facet, 9\% was attributable to the student by rater within classroom interaction, $4.7 \%$ to the rater within classroom, and $2.4 \%$ of the variance attributable to the instrument was negligible. The small amount of variance found between instruments suggests that the BASC-2 and ASEBA assessed 
very similar constructs. Likewise, variance between raters within classrooms (4.7\%) was almost double the difference attributable to instrument, indicating rater differences contributed a higher percentage of variance to the model than the choice of measurement. Interestingly, Bergeron and colleagues' dependability coefficient was calculated at .68 , failing to meet the .70 criteria for use as a screening measure as suggested by Salvia and colleagues (2010). The low dependability coefficient (.68) suggests that sources of systematic error (e.g., classroom and student rater within classroom effects) may have impacted the generalizability of scores in this sample. The lack of D study analyses in Bergeron et al. investigation limits the application of findings and dependability of study procedures, as this information could have provided the number of teachers and occasions that would be needed to obtain more dependable data.

Generalizability theory and brief behavior rating scales. Volpe and colleagues (2011) used GT to create an optimal measurement procedure, including how many assessment occasions and the number of items needed to obtain dependable data. This study utilized the Conners' Teacher's Rating Scale (Conners'; Loney \& Milich, 1982), a scale that assess inattentive, overactive, impulsive, and oppositional behavior, to monitor the responses of 71 children (ages 6-13) in both placebo and medication conditions. Teachers were asked to rate each student four times over two weeks. Two Connors' subscales were assessed to monitor changes, including inattentive-over activity (IO) and oppositional-defiant (OD) scores.

Separate G and D studies for each subscale and medication condition were conducted to examine the influence of person (p), item (i), and occasion (o). For placebo and medication conditions, the person accounted the most variance at (34\%-37\% IO; 40\%-48\% OD) of total variance along the two subscales examined. A large portion of variance was attributed to the person by occasion interaction ( $21 \%$ IO, $21-25 \%$ OD). The person by item interaction accounted 
for less variance $(13 \%-15 \% \mathrm{IO}, 8-12 \% \mathrm{OD})$ and the portion attributable to item accounted for the least amount of variance $(10 \%-16 \% \mathrm{IO}, 1 \% \mathrm{OD})$. However, a large portion of unaccounted variance was also observed $(21 \% \mathrm{IO}, 18-26 \% \mathrm{OD})$, suggesting that a facet may have been hidden or should have been included in the model. Based on the overall percentage of variance attributed to person, it would suggest that this procedure was assessing medication changes over time, which increased the amount of variance attributable to occasion.

Volpe and colleagues also calculated dependability and generalizability coefficients $(\rho)$. During the placebo and medication conditions, dependability and generalizability coefficients were similar $(\rho=80)$. During the placebo and medication conditions, dependability and generalizability coefficients on the OD subscale were also similar and above .80 . These results suggest that overall measurement procedures produced dependable data as coefficients approached or exceeded the .80 criterion recommended by Salvia, Ysseldyke, and Bolt (2010). As conducting four measurements over two weeks may not be feasible for a school when limited time and resources may be a concern, a follow-up D study was conducted. Results demonstrated that a single item could not produce dependable data, even when students were assessed on 20 occasions. When five items in each subscale were used, the number of assessments needed to obtain dependable data was decreased to four. However, the effect of increasing item sample size above 5 had little effect on the generalizability and dependability of the measure, contrasting what would typically happen when increasing the number of items on a measure (Briesch et al., 2014). These results highlight how measurement procedures can be manipulated and then analyzed in an effort to create more efficient assessment procedures.

\section{Summary and Conclusions}


Increased recognition of students' often unmet mental health needs has led to the development and adoption of multi-tiered systems of support (MTSS) in schools. As a model for proactively identifying, preventing, and supporting students' social, behavioral, and emotional development, MTSS hold many benefits over the traditional referral-based method and concomitant reactive treatment options. However, much of the treatment approach in MTSS is founded on surveillance and "depends on the accurate definition, identification, and thus, detection of problem behavior" (Miller et al., p. 2). As the modality in which surveillance is accomplished, universal screening for BER is a foremost consideration of the ability of schoolbased MTSS to meet the mental health needs of students'. However, surveillance data must be gathered by methods that are acceptable to schools. As the adoption of screening for BER lags behind that of academic screening, current research on universal screening procedures have led to the development screening measures that are contextually appropriate and highly usable (Glover \& Albers, 2007). Notably, BBRS are promising brief and efficient means of collecting surveillance data.

As BBRS are used to identify students requiring school-based services, it is important that they generate meaningful data. However, most research to date has examined the psychometric properties of BBRS from a CTT perspective. The conceptualization of measurement error under CTT fails to capture the complex nature of screening within school settings, as CTT considers measurement error random, does not for sources of measurement error to be examined simultaneously, and cannot evaluate an absolute referenced criterion score. Although this traditional approach provides information about the precision of this measurement tool, the use of teacher ratings of student behavior in school constitutes a significant departure from the strict-laboratory control in which CTT was developed. Therefore, it is entirely 
plausible that the nature of measurement error in school-based universal screening procedures is (1) systematic and (2) that the impact of teacher selection, measurement choice, and screening occasion differentially affect the meaningfulness of data.

As an alternative to CTT, GT has been suggested as one strategy that can account for the error variance attributed to various sources (e.g., teacher, classroom, timing of screening) integral to school-based universal screening procedures. A benefit of GT is the acknowledgement of the differential contributions of rater selection, measurement choice, and testing occasion on the ability of a screening measure to provide meaningful information. Furthermore, GT can be used to maximize dependability and generalizability of universal screening procedures enabling school practitioners to better meet the behavioral needs of their students. Previous studies using GT suggest that sources of systematic error variance not only affect the meaningfulness of data; they also suggest that measurement procedures can be modified to create more meaningful and efficacious data.

First, to the primary investigators knowledge, no previous research has explored the application of GT to universal screening procedures for BER. Therefore, the current study addresses a gap in the literature by using GT to examine the amount of measurement error of rater, occasion, and measure within screening.

Second, in order to examine the reliability of these screening procedures with CTT, traditional reliability coefficients were used to examine the reliability of time (occasion), rater, and instrument in isolation. Specifically, these reliability coefficients were evaluated against the .80 for criterion required for screening, as referenced by Salvia, Ysseldyke, and Bolt (2010). This study contributes to the literature by providing information regarding the ability of a 
universal screening measure to provide meaningful data through the lens of CTT and a means to compare traditional reliability coefficients to dependability and generalizability coefficients. Third, this study investigated the amount of error variance that components of the measurement procedure contribute to the total variance observed in screening data. The implication of rater variance for the practice of screening in schools depends on the percentage of variance attributable to these components. If a small amount of variance is attributable to any of these components, then we can be assured that screening is adequately assessing the risk level of students. However, if a large percentage of variance is found in any of the facets, then adjustments to the measurement procedure may need to be made. For example, if there is a large amount of variance attributable to the facet of rater, this indicates that the differences in scores may be due to how teachers are differentially rating each student. These results may indicate more teachers should rate each student or that more formal teacher training may be required on what student behaviors are being rated on a screening measure. Given that BER is thought to be a trait, and therefore stable, a large percentage of variance attributable to occasion, would indicate that more screening occasions would be needed to provide a dependable estimate of a students' level of risk. Lastly, large amounts of variance attributable to measure would indicate that two screeners are assessing different constructs. However, if the scores are similar, then a school could reasonably select either screener and still attain dependable data.

Fourth, this study investigated the impact of nesting on the percentage of variance attributable to students within rater and a fully crossed model. Because students are naturally nested within raters (i.e., rated by teachers), this study provides potentially valuable results by documenting descriptive information regarding the quantity of error attributed to the confounding effect of nesting on student and rater variance. This study will examine the 
variance occurring in three classrooms in isolation to determine what percentage of variance of the obtained student scores is attributable to student, rater, different occasions, measures, and/or the interactions between these variables.

Finally, this study explored the generalizability of alternative measurement procedures through a decision study (D study). By increasing sample size of facets and observing the impact of that on the generalizability coefficient of the measurement procedure it is anticipated that the results of the D study will be used to suggest the number of teachers and occasions needed to maximize the efficiency and meaningfulness of screening data. For example, if screening measures are administered three times per year, the use of two teachers may produce more dependable data as compared to a single administration. Similarly, if only having one teacher rate each students, more dependable data may be generated if a screener is given five times per year as compared to three. The overall purpose of the study is to use GT to offer means of improving universal screening in schools. 


\section{Chapter III: Method}

\section{Participants and Setting}

Primary participants included three teacher pairs $(n=6)$ recruited from a single suburban middle school in the southwestern United States. The middle school participating in the current study was selected due to its interest in school-based behavior screening and use of a co-teaching model in which a special education and general education teacher share teaching responsibilities for a single classroom. There is one co-taught language arts classroom at each grade level (i.e., sixth, seventh, and eighth grades). As both teachers oversee all students in their classroom, special education and general education teachers have similar opportunities to observe and interact with all students, increasing the validity of their ability to rate student's behavior on BBRS. These data are then used to evaluate the rater variance between two teachers.

All six of the teachers hold state level teaching certifications. Four of the teachers have bachelor's degrees and two have master's degrees. Teachers have between 1.5 and 14 years of teaching experience $(M=8.42, S D=4.86)$. All teachers are female, and one teacher is Hispanic while the rest are Caucasian (see Table 1 for a summary).

Table 1

Summary of Teacher Background

\begin{tabular}{ccccccc}
\hline Teacher & \multicolumn{5}{c}{ Classroom (Grade) } \\
\cline { 2 - 6 } Attribute & \multicolumn{2}{c}{ A (Sixth) } & \multicolumn{2}{c}{ B (Seventh) } & \multicolumn{2}{c}{ C (Eighth) } \\
\hline Specialty & General & Special & General & Special & General & Special \\
Degree & Master's & Bachelor's & Bachelor's & Master's & Bachelor's & Bachelor's \\
Years of & 10 & 11 & 14 & 12 & 2 & 2 \\
Experience & & Female & Female & Female & Female & Female \\
Gender & Female & White & White & White & White & White \\
Race/Ethnicity & Hispanic & Whyycr
\end{tabular}


As teacher ratings of student behavior are of interest in the current study, students comprise the secondary participants. Consent was obtained from parents of all participating students prior to data collection, in accordance with University Human Subjects Institutional Review Board-approved procedures. Sample participants included 82 students (39 females and 43 males $)$ in grades six, seventh, and eighth. The mean size of each classroom is $26.86(S D=$ .94) students, ranging from 26 to 28 students. The mean student age is $12.4(S D=1.05)$ years, ranging from 11 to 14 years of age. Approximately 64\% of students are White/Caucasian, 20\% Hispanic/Latino, 5\% Black/African American, 3\% Asian, 3\% American Indian/Native American, and $31 \%$ of students are eligible for free or reduced-cost lunch.

\section{Measures}

To estimate the variance between measures, two brief behavior rating scales were selected to assess student levels of behavioral and emotional risk in the current study. The following measures were selected as they are similar in content coverage and are exemplars of BBRS that have been used in previous universal screening practices and studies (e.g., Eklund \& Dowdy, 2012; Goodman, 2004; Kilgus et al., 2014; Miller et al., 2015).

Social, Academic, and Emotional Behavior Risk Screener. The Social, Academic, and Emotional Behavior Risk Screener - Teacher Rating Scale (SAEBRS) is a brief rating scale designed for universal screening to identify students who may be at-risk for developing behavioral, social, emotional, and academic concerns (Kilgus, Chafouleas, Riley-Tillman, \& von der Embse, 2013). The SAEBRS consists of 19 total items, scaled on a 4-point Likert scale (anchored by Never, Sometimes, Often, Almost Always) to identify the frequency of behaviors across three domains: Social Behavior, Academic Behavior, and Emotional Behavior. The SAEBRS was selected as the measurement tool in the current study as it has demonstrated 
evidence of being (1) contextually appropriate, (2) usable, and (3) technically adequate across elementary and middle school samples (Kilgus, Chafouleas, \& Riley-Tillman, 2013; Kilgus, Eklund, von der Embse, \& Taylor, 2014; Kilgus, Sims, von der Embse, \& Riley-Tillman, 2014). For middle school students, internal consistency estimates were as follows: social subscale (.93), academic subscale (.93), emotional subscales (.77) and total scales (.94).

Strengths and Difficulties Questionnaire. The Strengths and Difficulties Questionnaire, Teacher Form (SDQ; Goodman, 1997) is a brief behavioral screening questionnaire used to assess children 3-16 years of age on five subscales. The SDQ consists of 25 items used to calculate five scales including emotional problems, conduct problems, hyperactivity/inattention problems, peer relationship problems, and prosocial behavior. Items are assessed on a 3-point Likert scale ranging from "not true" to "certainly true". The SDQ has demonstrated evidence of being contextually appropriate, usable, and technically adequate among use with school-aged populations (Goodman, 2004; Miller et al., 2015). The teacher form reported internal consistency, and Cronbach's alpha scores were as follows: total score ( $a=$ .87), Emotional Symptoms $(a=.78)$, Conduct Problems $(a=.74)$, Hyperactivity-Inattention ( $a$ $=.88)$, Peer Problems $(a=.70)$, and Prosocial behavior $(a=.84)$. Test-retest reliabilities were as follows: the total score $(a=.80)$, and Emotional Symptoms $(a=.65)$, Conduct Problems ( $a=$ $.69)$, Hyperactivity-Inattention $(a=.82)$, Peer Problems $(a=.72)$, and Prosocial Behavior ( $a=$ .74; Goodman, 2004).

\section{Procedures}

Recruitment. The researcher met with the school principal to explain the goals of the study and to obtain consent for participation. Once school administrative consent had been obtained, the researcher met with the six participating teachers to provide background 
information about the study, including a brief overview of school-based behavior screening. To ensure that teachers remained objective throughout the current study, they were not told about the researcher's interest in rater, occasion, and method. Following teacher consent, parent optout consent forms were provided for all students in each teacher's classroom with instructions regarding the distribution of consent forms. Three students returned parent forms requesting to not participate in the current study. The school and each participating teacher were provided a modest stipend for participating in the study.

Data collection. As screening is typically conducted multiple times during the school year (Burns et al., 2013), data were collected over two administration sessions (i.e., November 2015 and February 2016). Two screening occasions resulted in the calculation of an occasion facet, or variance due to different occasions. During each administration, teachers were given time to independently complete screening measures for each student in their classroom. Teacher pairs were given pre-labeled packets that included the SDQ and the SAEBERS for every student in their classroom. Both the order of the students and order of the screener were randomized to minimize order effects. The current researcher was available to answer questions and to ensure adherence to study protocol. Student demographic data (i.e., date of birth, race/ethnicity, grade) were gathered from the school's electronic record database.

Data entry verification. In order to verify the integrity of data entry, all SAEBRS $(n=$ $328)$ and SDQ $(n=328)$ rating scales were independently double-entered by two research assistants. The two separate datasets were compared using SPSS's compare datasets feature. This analyses showed a $94.3 \%$ agreement rate between entries. All disagreements between researchers were individually checked for accuracy against the original data sheet, with the 
master data file revised according to the value observed in the original sheet until agreement equaled $100 \%$ of entered data.

Missingness. Based on the specified measurement model (82 students $\times 2$ teachers $\times 2$ occasions $\times 2$ methods), a total of 656 individual ratings were possible. Of this figure, six ratings were missing (.9\%) across four students' records. The primary reasons for missing data included two students transferring to another school and teachers missing items on a screening measure, thus making a total score for BER impossible to calculate $(n=2)$. As each participating student should have a total of eight records, these four students' results were excluded (i.e., deleted pairwise) from generalizability analyses to ensure that both teachers had equal numbers of ratings for each student. A total of 624 ratings were included in the current analyses.

\section{Data Analysis Plan}

All screening data were entered and scored in SPSS using scoring syntax obtained from each screening measures primary authors.

Descriptive statistics and dichotomous analyses. Data analyses occurred over several steps. Initially, descriptive statistics were calculated separately for the SDQ and SAEBRS to obtain mean, standard deviation, and range of scores for each teacher and screening occasion, permitting the examination of score differences between classrooms and teachers. Next, scores obtained from each of the screening measures (i.e. SDQ, SAEBRS) were transformed into dichotomous variables, rating each student as "at-risk" or "not at-risk." Scores less than 36 on the SAEBRS Total Behavior scales were recoded as at-risk (Kilgus, Eklund, von der Embse, Taylor, C., \& Sims, 2016); while total difficulties scores above 11 on the SDQ were coded as atrisk (Goodman, 1997). The resulting dichotomous variable and accompanying analyses 
provided information regarding the nature of score differences, including base rates and levels of agreement between teachers, classrooms, and screening occasions.

Correlational analyses. Correlational analyses were conducted to examine the first research question (e.g., What is the test-retest, inter-rater reliability, and concurrent validity of brief behavior rating scales?). All correlations were calculated using SAEBRS and SDQ raw scores. In order to assess the first research question, analyses used traditional reliability coefficients to assess differences due to different occasions (i.e., test-retest reliability), difference in teacher ratings (i.e., inter-rater reliability), and differences between screening measures (i.e., concurrent validity reliability) were calculated.

Generalizability analyses. Z-scores were used for generalizability analyses involving a facet of measure, as scale differences between the SDQ and SAEBRS Total Behavior necessitated a linear equating procedure. If $\mathrm{G}$ studies were computed with raw scores, the differences in each screener's scales would result in an artificially high percentage of variance attributable to the facet of measure (Briesch et al, 2014). As the SAEBRS is positively scaled (i.e., lower scores indicate higher levels of student risk) with 19 items and the SDQ is negatively scaled (i.e., higher scores are indicative of higher risk levels) with 25 items, z-scores permitted cross comparisons to be made between measures. The SAEBRS Total Behavior raw score was converted into a z-score and calculated based on the respective means and standard deviations for each administration. To account for differences in scale direction, students' SDQ Total Difficulties z-scores were multiplied by a value of negative one. Generalizability analyses were used to address the second research question (e.g., What percentage of variance in data derived from screening scores is attributable to differences between students, teachers, occasions, measures, and/or the interactions between these factors?), by ascertaining the percentage of 
variance in screening scores that are attributable to student differences, teachers, occasions, measures, and/or the interactions between these facets. To assess the differential impact of these factors, generalizability analyses occurred over three model steps or model types (see Figure 1). These three model types are discussed in depth below.

The first step of generalizability analyses used a mixed s:r x o x m model, where data was examined for the entirety of the sample, using all students as they are nested within raters (s.r), over both screening occasions (o) and both screeners (m). As two teachers from each classroom rate each student in that classroom, students are nested within raters (s.r) in this model. An advantage of using nested data is that the full sample size can be utilized, therefore providing the most stable estimates of variance components (Brennan, 2001). However, a disadvantage of nested data is that several variance components are confounded in this model and the percentage of variance they attribute to the overall model cannot be estimated independently. In the current study, nested student within rater variance component confounds the student main effect with the student by rater interaction. The student by rater interaction is of particular interest in the current study, as it provides information regarding the presence of potential rater bias. Another disadvantage of nested data is that the main effect and resulting interactions of rater cannot be manipulated in D studies. As such, no D studies were conducted within this model, as it limits the data's usefulness when attempting to optimize the conditions of measurement. See Table 2 for a description of each facet in the mixed s:r x o x m model. Thus, another set of generalizability analyses were needed to do away with the problems of nested data. 


\section{Table 2}

Descriptions of Facets in Mixed s:r x o x m Model

\begin{tabular}{cc}
\hline Facet & Description \\
\hline Students $(s: r)$ & Object of measurement; Variability due to \\
students nested within raters \\
Rater $(r)$ & Variability due to raters \\
Occasions $(o)$ & Variability due to the different occasions \\
Measure $(m)$ & Variability due to screening measure \\
Student by Occasion within Rater $(s o: r)$ & Variability due to o x s:r interaction \\
Student by Measure within Rater $(s m: r)$ & Variability due to m x s:r interaction) \\
Raters by Occasions $(r o)$ & Variability due to r x o interaction \\
Raters by Measure $(r m)$ & Variability due to r x m interaction \\
Occasions by Measure $(o m)$ & Variability due to o x m interaction \\
Rater by Occasion by Measure $(r o m)$ & Variability due to r x o x m interaction \\
Student by Occasion by Measure with & Variability due to s:r x o x m interaction plus \\
Rater plus any Residual Error $(s o m: r, e)$ & residual error \\
\hline
\end{tabular}

The second step of generalizability analyses attempted to overcome limitations of nested data by examining each classroom separately. In this second step, three (one for each classroom) resulting fully crossed (mixed s x r x o x m) models were calculated. A benefit of these fully crossed models are that all 15 variance components are estimated, and the facet of rater can be manipulated in D studies (see Table 3). Although a drawback of examining individual classroom is reduced sample size placing variances components as at risk of being unstable, benefits of examining classroom individually is that decision studies can be conducted on all all main effects and the relative impact of student and rater main effects is discernable (Brennan, 2001; Cronbach et al., 1972). D studies were conducted at the classroom level using the information gathered from these mixed s x r x o x m G studies. 
Table 3

Descriptions of Facets in Mixed s x r x o x m Model

\begin{tabular}{|c|c|}
\hline Facet & Type of Variation \\
\hline Student $(s)$ & Object of Measurement \\
\hline Rater $(r)$ & Variability due to inconsistency between raters \\
\hline Occasion $(o)$ & Variability due to the different occasions \\
\hline Measure $(m)$ & Variability due to screening measure \\
\hline Student-by-Rater (sr) & Variability due to $\mathrm{s} x \mathrm{r}$ interaction \\
\hline Student-by-Occasion ( $\mathrm{so}$ ) & Variability due to $\mathrm{s} x \mathrm{o}$ interaction \\
\hline Student-by-Measure $(\mathrm{sm})$ & Variability due to $\mathrm{s} x \mathrm{~m}$ interaction \\
\hline Rater-by-Occasion (ro) & Variability due to $\mathrm{r} x \mathrm{o}$ interaction \\
\hline Rater-by-M (rm) & Variability due to $\mathrm{r} \times \mathrm{m}$ interaction \\
\hline Occasion-by-Measure (om) & Variability due to $\mathrm{o} x \mathrm{~m}$ interaction \\
\hline Student-by-Rater-by-Occasion (sro) & Variability due to $\mathrm{s} \times \mathrm{r} \times \mathrm{o}$ interaction \\
\hline Rater-by-Occasion-by-Measure (rom) & Variability due to $\mathrm{r} x$ o $\mathrm{x} \mathrm{m}$ interaction \\
\hline Student-by-Occasion-by-Measure (som) & Variability due to $\mathrm{s} \times \mathrm{ox}$ m interaction \\
\hline Student-by-Rater-by-Measure (srm) & Variability due to $\mathrm{s} \times \mathrm{r} \times \mathrm{m}$ interaction \\
\hline Residual error (srom,e) & Variability due to $\mathrm{s} \times \mathrm{r} \times \mathrm{o} \times \mathrm{m}$ interaction and error \\
\hline
\end{tabular}

In contrast to the previously discussed mixed s:r $\mathrm{x}$ o x $\mathrm{m}$ and mixed $\mathrm{s} \times \mathrm{r} \times \mathrm{o} \times \mathrm{m}$ models, where the measure $(\mathrm{m})$ facet is treated as fixed, the third step of generalizability analyses did not include a facet of measure. As the interpretation of a fixed measure facet results in variance components that may not be intuitive because the measure facet is (mathematically) treated using the average of levels over the conditions of the measure facet (Shavelson \& Webb, 1991). This approach resulted in variance components that used an average of the SDQ and SAEBRS scores (Briesch et al., 2012; Shavelson et al., 1989). Universal screening for BER procedures are not known for using the average of two screening scores for decision making. However, generalizability theory provides another means of treating a fixed facet via a separate examination of the levels in a fixed facet (Brennan, 2001). Thus, the third set of models examined the SDQ and SAEBRS individually for each classroom. A benefit of examining the SDQ and SAEBRS separately is that interpretation of score effects are more closely aligned to actual use of the screening measures. This resulted in six separate random s x r x o models (three 
classrooms for each measure). See Table 4 for a description of each facet in the random $\mathrm{s} \times \mathrm{r} \times \mathrm{o}$ models. D Studies were also conducted with the information gathered by these analyses. Table 4

Descriptions of Facets in Random s x r x o Model

\begin{tabular}{cc}
\hline Facet & Type of Variation \\
\hline Student $(s)$ & Object of Measurement \\
Rater $(r)$ & Variability due to inconsistency between raters \\
Occasion $(o)$ & Variability due to different occasions \\
Student-by-Rater $(s r)$ & Variability due to s x r interaction \\
Student-by-Occasion $(s o)$ & Variability due to s x o interaction \\
Rater-by-Occasion $(r o)$ & Variability due to r x o interaction \\
Residual error $(s r o, e)$ & Variability due to s x r x o interaction plus error \\
\hline
\end{tabular}

Decision studies. Decision studies were conducted to examine the third research question (e.g., How does altering the number of raters and occasions affect the generalizability of universal screening scores?). Although the aforementioned generalizability studies enable the calculation of generalizability and dependability coefficients, they may be impractical for applied screening practices in schools due to the need for two raters, using two measures, on two occasions. However, the variance component estimates obtained in $\mathrm{G}$ studies are valuable as they now allow an analyses of the optimal conditions of measurement through a series of D studies. This, in turn, provides measurement conditions that may be more realistic and practical universal screening procedures.

The D studies conducted on the second (mixed $\mathrm{s} \times \mathrm{r}$ x o x m) and third (random $\mathrm{s} \times \mathrm{r}$ x o) models, involved an examination of the impact of increasing or decreasing sample sizes of occasion and rater on the generalizability coefficient $\left(\rho^{2}\right)$, which was then compared to a given acceptability criterion. In order to align with previous research on universal screening as a low stakes decision, as well as one that is more serious (Chafouleas et al., 2010), resulting 
generalizability and dependability coefficients were compared to small (.70) and medium effect sized (.80; Salvia, Ysseldyke, \& Bolt, 2010).

Although dependability coefficients $(\Phi)$ could be calculated with the variance components obtained above, dependability coefficients excluded student differences as a source of error (e.g., student, student and rater interaction) in calculations. As the current study posits that student level differences matter in universal screening, the error variance used in calculating the generalizability coefficient is more relevant to the current study. Although this point is nuanced, the decision to focus analyses on generalizability coefficients best reflected the types of relative-decision making that is likely to occur in universal screening practices.

D studies were conducted over a series of steps, using the information gathered from the second (mixed s x r x o x m model) and third (random s x r x o model) step of generalizability analyses to calculate generalizability coefficients $\left(\rho^{2}\right)$. In particular, the current study was interested in using decision studies to determine the number of raters and occasions necessary to attain generalizable data. First, the number of screening occasions, raters, and methods are reduced to a sample size of one, as this represents using a single screening measure during a single administration of measures. Of interest was examining the effect of increasing: (1) the number of occasions, while holding the number of raters and measures to a sample size of one; and (2) the number of raters, when holding the number of occasions and measures to a single sample size for each. See Figure 1 for a summary of generalizability and decision studies. 
Figure 1

Summary of Generalizability and Decision Studies

\begin{tabular}{|c|c|c|c|c|c|c|}
\hline $\begin{array}{l}\text { Mixed s:r x o x m } \\
\text { Model (Step One) }\end{array}$ & \multicolumn{2}{|c|}{$\begin{array}{l}\text { Mixed s x r x ox m } \\
\text { Models (Step Two) }\end{array}$} & \multicolumn{4}{|c|}{$\begin{array}{c}\text { Random s x r x o } \\
\text { Models (Step Three) }\end{array}$} \\
\hline $\begin{array}{c}\text { G study } \\
\text { for all classes and } \\
\text { raters }\end{array}$ & \multicolumn{2}{|c|}{$\begin{array}{l}\text { Separate G studies for } \\
\text { Classes A, B, \& C }\end{array}$} & \multicolumn{2}{|c|}{$\begin{array}{c}\text { Separate G studies for } \\
\text { Classes A, B, \& C } \\
\text { using SAEBRS }\end{array}$} & \multicolumn{2}{|c|}{$\begin{array}{c}\text { Separate } \mathrm{G} \text { studies for } \\
\text { Classes A, B, \& C } \\
\text { using SDQ }\end{array}$} \\
\hline & $\begin{array}{l}\text { Separate } \\
\text { D studies } \\
\text { for } \\
\text { occasion }\end{array}$ & $\begin{array}{c}\text { Separate } \\
\text { D studies } \\
\text { for } \\
\text { Rater }\end{array}$ & $\begin{array}{l}\text { Separate } \\
\text { D studies } \\
\quad \text { for } \\
\text { occasion }\end{array}$ & $\begin{array}{c}\text { Separate } \\
\text { D studies } \\
\text { for } \\
\text { Rater }\end{array}$ & $\begin{array}{l}\text { Separate } \\
\text { D studies } \\
\quad \text { for } \\
\text { occasion }\end{array}$ & $\begin{array}{l}\text { Separate } \\
\text { D studies } \\
\text { for } \\
\text { Rater }\end{array}$ \\
\hline
\end{tabular}

Note. G study = generalizability study; D study = decision study. 


\section{Chapter IV: Results}

\section{Descriptive Statistics}

Descriptive statistics were first calculated for BER ratings across the two raters for each occasion and screening measure (see Table 5 for the SAEBRS descriptive statistics and Table 6 for SDQ descriptive statistics). A repeated measure factorial analysis of variance (ANOVA) was conducted to examine if any significant differences between the scores assigned by each teacher type, classroom, and occasion for the SAEBRS raw scores were present, as such differences would provide evidence of error attributable to classroom, teacher type, and occasion. A significant main effect was found for teacher type $F(1,300)=19.85, p<.001, \eta^{2}=.06$, with mean ratings on special education SAEBRS raw scores being higher (49.9-50.56) than general education teachers mean raw scores (44.85-45.79) at both fall and spring administrations.

Table 5

SAEBRS Descriptive Statistics

\begin{tabular}{|c|c|c|c|c|c|}
\hline \multirow[b]{2}{*}{ Classroom } & \multirow[b]{2}{*}{ Statistic } & \multicolumn{2}{|c|}{ Fall } & \multicolumn{2}{|c|}{ Spring } \\
\hline & & Special & General & Special & General \\
\hline \multirow{4}{*}{ A } & $M$ & 52.12 & 45.28 & 52.4 & 45.6 \\
\hline & $S D$ & 8.08 & 13.22 & 7.22 & 15.02 \\
\hline & Minimum & 28 & 8 & 28 & 6 \\
\hline & Maximum & 57 & 57 & 57 & 57 \\
\hline \multirow{4}{*}{ B } & $M$ & 49.46 & 39.19 & 51.5 & 43.31 \\
\hline & $S D$ & 11.72 & 14.85 & 9.02 & 11.8 \\
\hline & Minimum & 22 & 8 & 18 & 17 \\
\hline & Maximum & 57 & 57 & 57 & 57 \\
\hline \multirow{4}{*}{$\mathrm{C}$} & $M$ & 48.33 & 49.89 & 47.65 & 48.52 \\
\hline & $S D$ & 4.60 & 6.87 & 4.90 & 7.47 \\
\hline & Minimum & 38 & 34 & 36 & 30 \\
\hline & Maximum & 57 & 57 & 56 & 57 \\
\hline \multirow{4}{*}{ All } & $M$ & 49.92 & 44.85 & 50.56 & 45.79 \\
\hline & $S D$ & 8.63 & 12.71 & 7.38 & 11.78 \\
\hline & Minimum & 22 & 8 & 18 & 6 \\
\hline & Maximum & 57 & 57 & 57 & 57 \\
\hline
\end{tabular}


A second repeated measure factorial ANOVA was conducted to examine differences between teacher type, occasion, and grade using the SDQ raw scores. Once again, there was a significant main effect for teacher type, $F(1,311)=11.52, p=.001, \eta^{2}=.04$. Special education teacher average student ratings on SDQ raw scores were lower (3.44-4.04) than general education teachers (6.52-5.94) for each administration occasion. A significant main effect was also present when examining classrooms differences, $F(2,300)=11.52, p=.009, \eta^{2}=.03$. Post hoc tests with a Bonferroni correction, whereby the significance criterion was set at $p<.016$ (.053), demonstrated significant differences between Classroom C $(M=3.92, S D=3.50)$ and Classroom B $(M=6.57, S D=8.10)$ at the $p<.01$ level.

Table 6

SDQ Descriptive Statistics

\begin{tabular}{|c|c|c|c|c|c|}
\hline \multirow[b]{2}{*}{ Classroom } & \multirow{2}{*}{$\begin{array}{c}\text { Descriptive } \\
\text { Statistic }\end{array}$} & \multicolumn{2}{|c|}{ Fall } & \multicolumn{2}{|c|}{ Spring } \\
\hline & & Special & General & Special & General \\
\hline \multirow{4}{*}{ A } & $M$ & 2.72 & 6.12 & 2.84 & 6.32 \\
\hline & $S D$ & 5.66 & 7.96 & 5.74 & 9.59 \\
\hline & Minimum & 0 & 0 & 0 & 0 \\
\hline & Maximum & 21 & 21 & 27 & 33 \\
\hline \multirow{4}{*}{ B } & $M$ & 5.96 & 9.85 & 4.23 & 6.23 \\
\hline & $S D$ & 8.61 & 9.87 & 6.37 & 6.37 \\
\hline & Minimum & 0 & 0 & 0 & 0 \\
\hline & Maximum & 30 & 27 & 22 & 20 \\
\hline \multirow{4}{*}{$\mathrm{C}$} & $M$ & 3.41 & 3.70 & 3.26 & 5.30 \\
\hline & $S D$ & 2.56 & 3.84 & 2.93 & 4.23 \\
\hline & Minimum & 0 & 0 & 0 & 0 \\
\hline & Maximum & 10 & 14 & 12 & 16 \\
\hline \multirow{4}{*}{ All } & $M$ & 4.04 & 6.52 & 3.44 & 5.94 \\
\hline & $S D$ & 6.18 & 7.93 & 5.16 & 6.93 \\
\hline & Minimum & 0 & 0 & 0 & 0 \\
\hline & Maximum & 30 & 31 & 27 & 33 \\
\hline
\end{tabular}

\section{Dichotomous Variable Analyses}

Individual base rates. Individual base rates indicated special education teachers identified approximately 5 to $10 \%$ of students as at-risk regardless of screening measure used 
and occasion. In contrast, general education teachers in Classrooms A and B identified a higher percentage of students (20\%) as at risk across screening measure, and occasion. Regarding

Classroom $\mathrm{C}$, the general education teacher rated a lower percentage of students as demonstrating BER as compared to the special education teacher. See Table 7 for a summary of individual base rates.

Table 7

Base Rates

\begin{tabular}{|c|c|c|c|c|c|c|}
\hline \multirow[b]{2}{*}{ Classroom } & \multirow[b]{2}{*}{ Teacher } & \multirow[b]{2}{*}{ Risk Level } & \multicolumn{2}{|c|}{ Fall } & \multicolumn{2}{|c|}{ Spring } \\
\hline & & & SAEBRS & SDQ & SAEBRS & SDQ \\
\hline \multirow{4}{*}{ A } & \multirow{2}{*}{ Special } & Not at risk & 92 & 92 & 96 & 96 \\
\hline & & At Risk & 8 & 8 & 4 & 4 \\
\hline & \multirow{2}{*}{ General } & Not at risk & 80 & 80 & 84 & 80 \\
\hline & & At Risk & 20 & 20 & 16 & 20 \\
\hline \multirow{4}{*}{ B } & \multirow{2}{*}{ Special } & Not at risk & 92 & 92 & 96 & 96 \\
\hline & & At Risk & 8 & 8 & 4 & 4 \\
\hline & \multirow{2}{*}{ General } & Not at risk & 80 & 80 & 80 & 80 \\
\hline & & At Risk & 20 & 20 & 20 & 20 \\
\hline \multirow{4}{*}{$\mathrm{C}$} & \multirow{2}{*}{ Special } & Not at risk & 89 & 93 & 89 & 93 \\
\hline & & At Risk & 11 & 7 & 11 & 7 \\
\hline & \multirow{2}{*}{ General } & Not at risk & 93 & 96 & 93 & 96 \\
\hline & & At Risk & 7 & 4 & 7 & 4 \\
\hline
\end{tabular}

Rater agreement. Regarding the levels of agreement by teachers, the percentage of agreement was calculated by assigning students to three groups based on teacher agreement: (a) if both teachers agreed that each student was not at risk, they were classified as "Both Agree Not At Risk"; (b) if both teachers agreed that each student was at risk, they were classified as "Both Agree At Risk"; and (c) if either teacher identified the student as at risk, while the other did not, they were classified as "Disagree At Risk". For all classrooms, teacher agreement ranged from 80 to $84 \%$ for both screening occasions and raters disagreed on 12 to $16 \%$ of at-risk students. No obvious differences were noted between occasions and screeners, with an exception of 
Classroom B that demonstrated the highest disagreement between teacher ratings of at-risk students (see Table 8 for a summary).

Table 8

Percentage of Teacher Agreement

\begin{tabular}{|c|c|c|c|c|c|}
\hline \multirow[b]{3}{*}{ Classroom } & \multirow[b]{3}{*}{ Teacher Agreement } & \multicolumn{2}{|c|}{ SAEBRS } & \multicolumn{2}{|c|}{ SDQ } \\
\hline & & Fall & Spring & Fall & Spring \\
\hline & & $\%$ & $\%$ & $\%$ & $\%$ \\
\hline \multirow{3}{*}{ A } & Both Agree Not At Risk & 80 & 84 & 80 & 80 \\
\hline & Disagree At Risk & 12 & 12 & 12 & 16 \\
\hline & Both Agree At Risk & 8 & 4 & 8 & 4 \\
\hline \multirow{3}{*}{ B } & Both Agree Not At Risk & 57 & 69 & 62 & 77 \\
\hline & Disagree At Risk & 23 & 27 & 19 & 12 \\
\hline & Both Agree At Risk & 19 & 4 & 19 & 12 \\
\hline \multirow{3}{*}{$\mathrm{C}$} & Both Agree Not At Risk & 89 & 89 & 93 & 89 \\
\hline & Disagree At Risk & 11 & 7 & 7 & 7 \\
\hline & Both Agree At Risk & 0 & 4 & 0 & 4 \\
\hline
\end{tabular}

\section{Correlational Analyses}

To address research question one, correlational analyses were conducted to examine the test-retest reliability, inter-rater reliability, and concurrent validity of the SAEBRS and SDQ, described below.

Test-retest reliability. To determine test-retest stability, Pearson correlation $(r)$ coefficients were calculated to assess correlations between scores obtained from fall and spring screenings. Guidelines were used to interpret the magnitude of correlations; coefficients smaller than .20 were considered weak, $.20-.80$ moderate, and those .80 and higher were considered strong (Hatcher \& Stepanski, 1994). Pearson correlation coefficients were computed using SAEBRS Total Score and SDQ Total Difficulties raw scores. Table 9 provides a summary of correlations. All correlations were significant at $p<.05$ level. Furthermore, all correlations were considered strong regardless of screener used, as all but two correlations exceeded .80 (range $=.75$ to .98$)$. These strong correlations suggest that test-retest reliability for data derived 
using the SAEBRS and the SDQ were strong.

Table 9

Test-Retest Correlation Coefficients

\begin{tabular}{cccccc}
\hline & \multicolumn{2}{c}{ SAEBRS } & & \multicolumn{2}{c}{ SDQ } \\
\cline { 2 - 3 } \cline { 5 - 6 } Classroom & Special & General & & Special & General \\
\hline A & .84 & .94 & & .79 & .98 \\
\hline B & .87 & .94 & & .95 & .91 \\
\hline C & .85 & .92 & & .75 & .90 \\
\hline All & .85 & .91 & & .87 & .87 \\
\hline
\end{tabular}

Note. All correlations are statistically significant at $\mathrm{p}<.01$

Inter-rater reliability. In order to assess rater variability, Spearman's rank correlation coefficient (rho) was calculated for SAEBRS Total Score and SDQ Total Difficulties raw scores. In contrast to the correlational analyses in this section examining concurrent and test-retest reliability, a nonparametric test (i.e., rho) was considered a more appropriate test because screening data at the rater level is likely to violate assumptions of normality, especially given the reduced sample size when used for only two raters. Utilizing Cohen's (1998) recommended effect sizes, correlations between 0.10 and 0.30 were considered weak, correlations between 0.30 and 0.50 were considered moderate, and correlations greater than 0.50 were considered strong. All correlations fell in the strong range and were statically significant $(\mathrm{p}<.01$; range $=.57-.91)$ indicating strong inter-rater reliability correlations at both fall and spring screening across classrooms (see Table 10).

Table 10

Interrater Reliability Spearman (Rho) Correlation Coefficients

\begin{tabular}{cccccc}
\hline & \multicolumn{2}{c}{ SAEBRS } & & \multicolumn{2}{c}{ SDQ } \\
\cline { 2 - 3 } \cline { 5 - 6 } Classroom & Fall & Spring & & Fall & Spring \\
\hline A & 0.88 & 0.83 & & 0.67 & 0.91 \\
\hline B & 0.73 & 0.85 & & 0.73 & 0.86 \\
\hline C & 0.73 & 0.78 & & 0.75 & 0.71 \\
\hline All & 0.57 & 0.67 & & 0.63 & 0.85 \\
\hline
\end{tabular}

Note. All correlations were statistically significant at $\mathrm{p}<.01$ 
Concurrent validity. Pearson product-moment correlation coefficients (r) were calculated to examine the concurrent validity of the raw SAEBRS Total Score and the raw SDQ Total Difficulties score (see Table 8). Following Cohen's (1988) recommendations, correlations of .50 and higher were considered large. As expected negative correlations were observed due to scale differences between the SDQ and SAEBRS. Results from both screening measures demonstrated large correlations and were statistically significant $(p<.01)$. Fall screening scores demonstrated higher concurrent validity than those obtained in the spring.

Table 11

\begin{tabular}{cccc}
\multicolumn{4}{c}{ Pearson Correlation Coefficients for SDQ } \\
\hline \multirow{2}{*}{ Classroom } & Teacher & Fall & Spring \\
\hline \multirow{2}{*}{ A } & Special & -0.94 & -0.90 \\
& General & -0.96 & -0.97 \\
\hline \multirow{2}{*}{ B } & Special & -0.96 & -0.82 \\
& General & -0.94 & -0.93 \\
\hline \multirow{2}{*}{ C } & Special & -0.88 & -0.67 \\
& General & -0.90 & -0.80 \\
\hline \multirow{2}{*}{ All Classrooms } & Special & -0.92 & -0.79 \\
& General & -0.95 & -0.93
\end{tabular}

Note. All correlations were statistically significant at $p<.01$.

\section{Generalizability Studies}

To address research question two, a series of generalizability studies were conducted to examine the variance between students, raters, occasions, measures, and their interactions, further described below.

Step one: mixed s:r $\mathbf{x} 0 \times \mathbf{x}$ models. This model is a mixed three-facet, partially nested design, where students nested within rater (s.r) are considered the object of measurement, and are crossed with occasion (o) and the fixed measure (m) facets. The first step involved conducting a G study to estimate the variance associated with the following facets: rater (r), students nested within rater (s:r), occasion (o), screening measure (m), and their interactions. Variance 
components were calculated using the ANOVA procedure, in which a repeated measures factorial ANOVA is used to calculate the sums of squares (Type III) for each main effects and all possible interactions. As this data was not balanced (e.g., classrooms included different numbers of students), SPSS was used to calculate sums of squares for each main effect and interaction, which were then imported into the EduG software program to compute final estimated variance components. This was deemed necessary as EduG cannot compute variance components for unbalanced data. SPSS, however, is capable of handling unbalanced data. In the s:r x o x m design, there were eleven separate variance components that could be calculated: four main effects ([1] student within rater, [2] rater, [3] occasion, and [4] measure), six interactions ([1] student-by-occasion-within-rater, [2] student-by-measure-within-rater, [3] rater-by-measure, [4] rater-by-occasion, [5] occasion-by-measure, and [6] occasion-by-measure-by-rater) and the residual (unexplained) error term, representing the student-by-occasion-by-measure-within-rater, plus any unexplained variance within the model. Calculation of these variance components made it possible to examine the relative contribution of each facet to total variance. The results of the generalizability analyses are presented in Table 12. 
Table 12

Mixed s:r x о х $m$ G Study

\begin{tabular}{lccccc}
\hline \multicolumn{1}{c}{ Sources of Variation } & $\begin{array}{c}\text { Sums } \\
\text { of } \\
\text { Squares }\end{array}$ & df & $\begin{array}{c}\text { Mean } \\
\text { Squares }\end{array}$ & $\begin{array}{c}\text { Estimated } \\
\text { Variance } \\
\text { Component }\end{array}$ & $\begin{array}{c}\text { Percentage } \\
\text { of Total } \\
\text { Variance }\end{array}$ \\
\hline Student within Rater & 538.44 & 150 & 3.58961 & .85112 & 80.6 \\
Rater & 0 & 5 & 0 & -.03274 & 0 \\
Occasion & 0 & 1 & 0 & 0 & 0 \\
Measure & 0 & 1 & 0 & 0 & 0 \\
Student x Occasion within Rater & 27.77 & 150 & .18514 & .09257 & 8.8 \\
Student x Measure within Rater & 26.95 & 150 & .17968 & .06705 & 6.3 \\
Rater x Occasion & 0 & 5 & 0 & -.00356 & 0 \\
Rater x Measure & 0 & 5 & 0 & -.00258 & 0 \\
Occasion x Measure $_{\text {Residual SOM:R, }{ }^{1}}$ & 0 & 1 & 0 & 0 & 0 \\
Rater x Occasion x Measure $^{\text {Ren }}$ & 6.83 & 150 & .04558 & .04558 & 4.3 \\
\hline
\end{tabular}

${ }^{1}$ Residual SOM:R,e is the variance associated with student $\mathrm{x}$ occasion $\mathrm{x}$ measure within rater plus any additional error.

Across the 11 variance components that were calculated for this model, four were negative: (1) rater main effect (-.03274); (2) rater and occasion interaction (-.00356); (3) rater and measure interaction (-.00258); and (4) rater, occasion, and measure interaction (-.00175). Although variance by definition cannot be negative, negative variance components are possible in G theory and may be caused by several factors, including sampling variability, sample size, and model misspecification (Brennan, 2001; Cronbach et al., 1972). Model misspecification was ruled out as a contributing factor, as the magnitude of these negative values were found to be relatively small. Negative estimates were thereby set to equal zero for interpretation, as suggested by Cronbach and colleagues (1972).

The majority of variance observed in this model (81\%) was attributed to the nesting of student within rater (s:r), suggesting that individual differences in student's levels of BER were accounted for by teacher ratings. The next largest percentage of variance (9\%), although moderate, was attributed to the student-by-occasion nesting with rater facet. This suggests that a 
percentage of variance is attributed to different raters scoring individuals differently on the fall and spring screening administration. The third largest amount of variance was negligible (6\%) and can be attributed to the three way interaction of student, occasion, and measure, nesting within rater, plus any additional residual error (som:r,e). The student by measure within rater (sm:r) variance component accounted for $4.5 \%$ of variance, indicating that only a small percentage of variance was due to the selected screening measure. Variance components that contributed zero percent of variance were occasion, measure, rater and occasion, rater and measure, occasion and measure, and rater, occasion, and measure effects.

Step two: mixed $\mathbf{s} \times \mathbf{r} \mathbf{x} \mathbf{0} \times \mathbf{m}$ models. Three separate G studies were run within Classrooms A, B, and C to examine the percentage of variance attributable to student, rater, occasion, measure, and the interactions between these facets (mixed s x r x o x m design). These separate analyses were conducted to obtain variance components for student and rater main effects that are free of the confounding effects of nesting on variance component calculation. Accordingly, fully crossed mixed s x r x o x m models were calculated for each of the three classrooms in isolation. The results for each classroom are described separately.

The variance components for the three-facet, fully crossed design s x r x o x m were calculated in a similar manner to the nested model G study discussed above for each classroom. In a manner consistent with prior G theory behavioral assessment research (Chafouleas et al., 2010), raters and occasions were treated as random. As the implications of treating these facets as random are large, the current study feels this is justified, chiefly because it is (1) reasonable to assume that teachers and screening occasions used in the current study would produce data as an acceptable observation of BER, and (2) it is reasonable to assume that the teachers and occasions used in the current study are exchangeable with teachers and occasions in their respective 
universes. However, given the marked differences between screening tools as evidenced by the unique characteristics assessed by screening tools, the fixing of measure was deemed necessary as the SDQ and SAEBRS likely represent the entirety of the universe of acceptable screening measures, given that they assess similar behaviors. In this model, variance components representing the four main effects ([1] student, [2] rater, [3] occasion, and [4] measure), nine interactions ([1] student-by-rater, [2] student-by-occasion, [3] student-by-measure, [4] rater-byoccasion, [5] rater-by-measure, [6] occasion-by-measure, [7] student-by-rater-by-occasion, [8] rater-by-occasion-by-measure, [9] student-by-occasion-by-measure), and the residual (studentby-rater-occasion-measure, plus any other error) were also calculated.

Negative variance components were found for student by rater, student by occasion, student by measure, rater by measure, rater by occasion, and both three way interactions (see Table 13) in the mixed s x r x o x m model for Classroom A. As these negative variance components were small and near zero, this model was interpreted. In order from largest to smallest, student accounted for approximately $81 \%$ of variance, student by rater by occasion interaction accounted for approximately 13\%, the student by measure and residual accounted for approximately $2 \%$ each, and the student by rater by measure interaction accounted for approximately $1 \%$ of variance. The remaining facets contributed little or no variance. The sizeable student $\mathrm{x}$ rater $\mathrm{x}$ occasion interaction suggests that students were rated differently by each teacher at each occasion. However, the vast majority of variance is attributable to the variance present in student levels of BER. 
Table 13

Classroom A Mixed s x r x o x m G Study

\begin{tabular}{lccccc}
\hline \multicolumn{1}{c}{ Sources of Variation } & $\begin{array}{c}\text { Sums of } \\
\text { Squares }\end{array}$ & df & $\begin{array}{c}\text { Mean } \\
\text { Squares }\end{array}$ & $\begin{array}{c}\text { Estimated } \\
\text { Variance } \\
\text { Component }\end{array}$ & $\begin{array}{c}\text { Percentage } \\
\text { of Total } \\
\text { Variance }\end{array}$ \\
\hline Student & 171.939 & 24 & 7.16412 & .88998 & 81.3 \\
Rater & 0 & 1 & 0 & .00096 & 0.1 \\
Occasion & 0 & 1 & 0 & .00141 & 0.1 \\
Measure & 0 & 1 & 0 & -.00048 & 0 \\
Student x Rater & 4.457 & 24 & .18571 & -.02395 & 0 \\
Student x Occasion & 3.361 & 24 & .14004 & -.03536 & 0 \\
Student x Measure & 3.308 & 24 & .13783 & .02401 & 2.2 \\
Rater x Occasion & 0 & 1 & 0 & -.00563 & 0 \\
Rater x Measure & 0 & 1 & 0 & -.0005 & 0 \\
Occasion x Measure & 0 & 1 & 0 & .00015 & 0 \\
Student x Rater x Occasion & 6.756 & 24 & .2815 & .14075 & 12.9 \\
Student x Rater x Measure & 1.188 & 24 & .0495 & .0125 & 1.1 \\
Student x Occasion x Measure & .403 & 24 & .01679 & -.00385 & 0 \\
Rater x Occasion x Measure & 0 & 1 & 0 & -.00098 & 0 \\
Residual (SROM,e) & .588 & 24 & .0245 & .0245 & 2.2 \\
\hline
\end{tabular}

For Classroom B's mixed s x r x o x m model, all negative variance components were small and near zero, suggesting the interpretability of the Classroom B s x r x o x m G study (see Table 14). Approximately $72 \%$ of variance was attributed to student, followed by $13 \%$ for student and rater, $5 \%$ for student by rater by occasion, and $3 \%$ student by measure and the residual. The remaining facets contributed little variance. The sizeable interaction between student and rater $(12.6 \%)$ indicate that teachers are systematically rating specific students differently, and may indicate that a certain degree of rater bias (i.e., rater bias suggests that individual teachers have perceptions of certain students that disagree, and therefore create variance) is present in the BER scores of students (Hoyt \& Kerns, 1999). Similarly, the threeway interaction between student, rater, and occasion (5\% of total variance) indicated very few differences between scores could be attributed to fall and spring screening occasions. The remaining facets contributed little variance to the total model. 
Table 14

Classroom B Mixed s x r x o x m G Study

\begin{tabular}{lccccc}
\hline \multicolumn{1}{c}{ Sources of Variation } & $\begin{array}{c}\text { Sums of } \\
\text { Squares }\end{array}$ & df & $\begin{array}{c}\text { Mean } \\
\text { Squares }\end{array}$ & $\begin{array}{c}\text { Estimated } \\
\text { Variance } \\
\text { Component }\end{array}$ & $\begin{array}{c}\text { Percentage } \\
\text { of Total } \\
\text { Variance }\end{array}$ \\
\hline Student $^{1}$ & 168.73 & 25 & 6.7492 & 0.75838 & 72.6 \\
Rater $^{2}$ & 0 & 1 & 0 & -0.00507 & 0 \\
Occasion $^{3}$ & 0 & 1 & 0 & -0.00045 & 0 \\
Measure $^{4}$ & 0 & 1 & 0 & -0.00057 & 0 \\
Student x Rater & 15.886 & 25 & 0.63544 & 0.13176 & 12.6 \\
Student x Occasion & 3.878 & 25 & 0.15512 & 0.01168 & 1.1 \\
Student x Measure & 5.082 & 25 & 0.20328 & 0.0299 & 2.9 \\
Rater x Occasion & 0 & 1 & 0 & -0.00208 & 0 \\
Rater x Measure & 0 & 1 & 0 & -0.00084 & 0 \\
Occasion x Measure & 0 & 1 & 0 & -0.00015 & 0 \\
Student x Rater x Occasion & 2.71 & 25 & 0.1084 & 0.0542 & 5.2 \\
Student x Rater x Measure & 1.898 & 25 & 0.07592 & 0.02174 & 2.1 \\
Student x Occasion x Measure & 1.005 & 25 & 0.0402 & 0.00388 & 0.4 \\
Rater x Occasion x Measure & 0 & 1 & 0 & -0.00125 & 0 \\
Residual (SROM,e) & 0.811 & 25 & 0.03244 & 0.03244 & 3.1 \\
\hline
\end{tabular}

All negative variance components were small and near zero (see Table 15), suggesting the interpretability of the model in the mixed s x r x o x m model for Classroom $\mathrm{C}$. Approximately $69 \%$ of variance was attributable to the object of measurement (i.e., student), followed by $10 \%$ for the interaction between student, rater, and occasion. The student by rater, student by measure, the student by rater by measure, and residual each accounted for approximately $5 \%$ of the total variance. 
Table 15

Classroom C Mixed s x r x o x m G Study

\begin{tabular}{lccccc}
\hline \multicolumn{1}{c}{ Sources of Variation } & $\begin{array}{c}\text { Sums of } \\
\text { Squares }\end{array}$ & df & $\begin{array}{c}\text { Mean } \\
\text { Squares }\end{array}$ & $\begin{array}{c}\text { Estimated } \\
\text { Variance } \\
\text { Component }\end{array}$ & $\begin{array}{c}\text { Percentage } \\
\text { of Total } \\
\text { Variance }\end{array}$ \\
\hline Student & 167.237 & 26 & 6.43219 & 0.75554 & 69 \\
Rater & 0 & 1 & 0 & -0.00164 & 0 \\
Occasion & 0 & 1 & 0 & 0.00004 & 0 \\
Measure & 0 & 1 & 0 & -0.00104 & 0 \\
Student x Rater & 10.192 & 26 & 0.392 & 0.04428 & 4 \\
Student x Occasion & 5.479 & 26 & 0.21073 & -0.00104 & 0 \\
Student x Measure & 11.265 & 26 & 0.43327 & 0.05629 & 5.1 \\
Rater x Occasion & 0 & 1 & 0 & -0.00398 & 0 \\
Rater x Measure & 0 & 1 & 0 & -0.00199 & 0 \\
Occasion x Measure & 0 & 1 & 0 & -0.00086 & 0 \\
Student x Rater x Occasion & 5.587 & 26 & 0.21488 & 0.10744 & 9.8 \\
Student x Rater x Measure & 4.21 & 26 & 0.16192 & 0.05375 & 4.9 \\
Student x Occasion x Measure & 2.616 & 26 & 0.10062 & 0.0231 & 2.1 \\
Rater x Occasion x Measure & 0 & 1 & 0 & -0.00202 & 0 \\
Residual (SROM,e) & 1.415 & 26 & 0.05442 & 0.05442 & 5 \\
\hline
\end{tabular}

Summary of classrooms mixed s $x \boldsymbol{r} x \boldsymbol{x}$ m models. Taken together, across each of the classroom-specific mixed models, the largest percentage of variance in BER scores was attributable to difference among students, ranging from $69 \%$ to $81 \%$ (see Table 16). The main effects of rater, occasion, and measure demonstrated that these facets exert little influence on the total variance when compared to the individual differences between students. Similarly, only Classroom B demonstrated a large percentage of variance for the student by rater interaction, as compared to Classrooms A and C. This suggested that many scores were not heavily influenced by rater bias. Student by measure effects were present in all classrooms, but accounted for less than $5 \%$ of variance, suggesting that students are rated similarly across the SDQ and SAEBRS. 
The student by rater by occasion model accounted for the next highest percentage of variance ranging from approximately 5 to $13 \%$ across classrooms.

Table 16

Summary of Classroom mixed s $x$ r x o x $m$ G Studies

\begin{tabular}{|c|c|c|c|}
\hline & $\mathrm{A}$ & B & $\mathrm{C}$ \\
\hline Sources of Variation & $\%$ & $\%$ & $\%$ \\
\hline Student & 81.3 & 72.6 & 69 \\
\hline Rater & 0.1 & 0 & 0 \\
\hline Occasion & 0.1 & 0 & 0 \\
\hline Measure & 0 & 0 & 0 \\
\hline Student x Rater & 0 & 12.6 & 4 \\
\hline Student x Occasion & 0 & 1.1 & 0 \\
\hline Student x Measure & 2.2 & 2.9 & 5.1 \\
\hline Rater x Occasion & 0 & 0 & 0 \\
\hline Rater x Measure & 0 & 0 & 0 \\
\hline Occasion x Measure & 0 & 0 & 0 \\
\hline Student x Rater x Occasion & 12.9 & 5.2 & 9.8 \\
\hline Student x Rater x Measure & 1.1 & 2.1 & 4.9 \\
\hline $\begin{array}{l}\text { Student x Occasion x } \\
\text { Measure }\end{array}$ & 0 & 0.4 & 2.1 \\
\hline Rater x Occasion x Measure & 0 & 0 & 0 \\
\hline Residual (SROM,e) & 2.2 & 3.1 & 5 \\
\hline
\end{tabular}

Step three: random $\mathrm{S} \times \mathrm{r} \times \mathrm{o}$ models for SDQ and SAEBRS. The second method of treating a fixed facet involved examining each condition separately. In order to conduct a D study for each condition, the variance components for a two facet, fully crossed random design (s $\mathrm{x} r \mathrm{x}$ o) were calculated for the SDQ and SAEBRS for each classroom. The resulting six G studies resulted in a total of three main effects ([1] student, [2] rater, and [3] occasion), three interactions ([1] student-by-rater, [2] student-by-occasion, [3] rater-by-occasion), and the residual error term (student-by-rater-by-occasion, plus residual error). Each of these was calculated within each individual classroom.

SAEBRS random $\mathbf{S} \times \mathbf{r} \times$ o models. A sizeable negative variance component was 
estimated for the student by occasion interaction (see Table 17) for Classroom A. As mentioned above, such a large negative value can indicate model misspecification. However, the small sample size of the current study is a probable contributor, as is sampling variability. The vast majority of variance $(62.8 \%)$ resulted from student differences, followed by $14.3 \%$ for rater, $11.6 \%$ for student by rater interaction, and $11.2 \%$ for the residual. The remaining facets contributed little variance $(<1 \%)$.

Table 17

Classroom A SAEBRS Random s x r x o Model

\begin{tabular}{|c|c|c|c|c|c|}
\hline Sources of Variation & $\begin{array}{l}\text { Sums of } \\
\text { Squares }\end{array}$ & $d f$ & $\begin{array}{c}\text { Mean } \\
\text { Squares }\end{array}$ & $\begin{array}{l}\text { Estimated } \\
\text { Variance } \\
\text { Component }\end{array}$ & $\begin{array}{c}\text { Percentage } \\
\text { of Total } \\
\text { Variance }\end{array}$ \\
\hline Student & 10550.5 & 24 & 439.60417 & 99.21667 & 62.8 \\
\hline Rater & 1162.81 & 1 & 1162.81 & 22.52333 & 14.3 \\
\hline Occasion & 2.25 & 1 & 2.25 & 0.27667 & 0.2 \\
\hline Student x Rater & 1303.94 & 24 & 54.33083 & 18.31667 & 11.6 \\
\hline Student x Occasion & 146.5 & 24 & 6.10417 & -5.79667 & 0 \\
\hline Rater x Occasion & 0.01 & 1 & 0.01 & -0.7075 & 0 \\
\hline Residual (SRO,e) & 424.74 & 24 & 17.6975 & 17.6975 & 11.2 \\
\hline
\end{tabular}

No negative variance components were estimated in the G study for Classroom B SAEBRS random s x r x o Model (see Table 18). Most of the variance (54.8\%) resulted from student differences as rated by each teacher, followed by $21.6 \%$ for rater differences, $12.1 \%$ for student by rater interaction, and $6.3 \%$ for the residual. The other facets contributed little variance $(<5 \%)$. 
Table 18

Classroom B SAEBRS Random s x r x o Model

\begin{tabular}{|c|c|c|c|c|c|}
\hline Sources of Variation & $\begin{array}{c}\text { Sums } \\
\text { of } \\
\text { Squares }\end{array}$ & $\mathrm{df}$ & $\begin{array}{c}\text { Mean } \\
\text { Squares }\end{array}$ & $\begin{array}{c}\text { Estimated } \\
\text { Variance } \\
\text { Component }\end{array}$ & $\begin{array}{c}\text { Percentage } \\
\text { of Total } \\
\text { Variance }\end{array}$ \\
\hline Student & 12147.615 & 25 & 485.9046 & 104.27616 & 54.8 \\
\hline Rater & 2215.385 & 1 & 2215.385 & 41.15386 & 21.6 \\
\hline Occasion & 246.154 & 1 & 246.154 & 4.01155 & 2.1 \\
\hline Student $\mathrm{x}$ Rater & 1482.115 & 25 & 59.2846 & 23.67306 & 12.4 \\
\hline Student x Occasion & 536.346 & 25 & 21.45384 & 4.75768 & 2.5 \\
\hline Rater x Occasion & 28.038 & 1 & 28.038 & 0.61921 & 0.3 \\
\hline SRO,e & 298.462 & 25 & 11.93848 & 11.93848 & 6.3 \\
\hline
\end{tabular}

No negative variance components were estimated in this study for the Classroom $\mathrm{C}$ SAEBRS Random Model (see Table 19). Most of the variance (71.7\%) resulted from student differences, followed by $16.3 \%$ for student by rater interaction, and $8.8 \%$ for the residual. The other facets contributed less than $2 \%$ of the variance in this model.

Table 19

Classroom C SAEBRS Random s x r x o Model

\begin{tabular}{lccccc}
\hline & $\begin{array}{c}\text { Sums } \\
\text { of } \\
\text { Squares }\end{array}$ & $d f$ & $\begin{array}{c}\text { Mean } \\
\text { Squares }\end{array}$ & $\begin{array}{c}\text { Estimated } \\
\text { Variance } \\
\text { Component }\end{array}$ & $\begin{array}{c}\text { Percentage } \\
\text { of Total } \\
\text { Variance }\end{array}$ \\
\hline Student & 3243.667 & 26 & 124.75642 & 26.97222 & 71.7 \\
Rater & 26.009 & 1 & 26.009 & 0.08974 & 0.2 \\
Occasion & 24.083 & 1 & 24.083 & 0.25712 & 0.7 \\
Student x Rater & 404.741 & 26 & 15.56696 & 6.13248 & 16.3 \\
Student x Occasion & 119.667 & 26 & 4.60258 & 0.65029 & 1.7 \\
Rater x Occasion & 8.898 & 1 & 8.898 & 0.20726 & 0.6 \\
SRO,e & 85.852 & 26 & 3.302 & 3.302 & 8.8 \\
\hline
\end{tabular}

SDQ random s x $r$ x o models. In the Classroom A SDQ Random s x r x o Model, sizeable, negative variance components were estimated in this model for student by occasion and rater by occasion (see Table 20). Most of the variance $(71.5 \%)$ resulted from student differences, followed by $9.2 \%$ for rater, $8.9 \%$ for student by rater interaction, and $10.4 \%$ for the residual. 
The other components contributed little variance.

Table 20

Classroom A SDQ Random s x r x o Model

\begin{tabular}{|c|c|c|c|c|c|}
\hline Sources of Variation & $\begin{array}{c}\text { Sums } \\
\text { of } \\
\text { Squares }\end{array}$ & df & $\begin{array}{c}\text { Mean } \\
\text { Squares }\end{array}$ & $\begin{array}{l}\text { Estimated } \\
\text { Variance } \\
\text { Component }\end{array}$ & $\begin{array}{c}\text { Percentage } \\
\text { of Total } \\
\text { Variance }\end{array}$ \\
\hline Student & 4621.5 & 24 & 192.5625 & 44.43167 & 71.5 \\
\hline Rater & 295.84 & 1 & 295.84 & 5.695 & 9.2 \\
\hline Occasion & 0.64 & 1 & 0.64 & 0.065 & 0.1 \\
\hline Student $\mathrm{x}$ Rater & 419.66 & 24 & 17.48583 & 5.525 & 8.9 \\
\hline Student x Occasion & 90.86 & 24 & 3.78583 & -1.325 & 0 \\
\hline Rater x Occasion & 0.04 & 1 & 0.04 & -0.25583 & 0 \\
\hline $\mathrm{SRO}, \mathrm{e}$ & 154.46 & 24 & 6.43583 & 6.43583 & 10.4 \\
\hline
\end{tabular}

In the Classroom B random s x r x o model, no negative variance components were estimated (see Table 21). Most of the variance (65\%) came from student differences, followed by $12.6 \%$ for student by rater interaction, $8.3 \%$ for the residual, $5 \%$ for rater, $4.3 \%$ for occasion, and $3.8 \%$ for student by occasion. Rater and occasion contributed little variance.

Table 21

Classroom B SDQ Random s x r x o Model

\begin{tabular}{|c|c|c|c|c|c|}
\hline Sources of Variation & $\begin{array}{c}\text { Sums } \\
\text { of } \\
\text { Squares }\end{array}$ & $\mathrm{df}$ & $\begin{array}{c}\text { Mean } \\
\text { Squares }\end{array}$ & $\begin{array}{l}\text { Estimated } \\
\text { Variance } \\
\text { Component }\end{array}$ & $\begin{array}{c}\text { Percentage } \\
\text { of Total } \\
\text { Variance }\end{array}$ \\
\hline Student & 5302.279 & 25 & 212.09116 & 45.78308 & 65 \\
\hline Rater & 225.087 & 1 & 225.087 & 3.54462 & 5 \\
\hline Occasion & 185.779 & 1 & 185.779 & 3.02461 & 4.3 \\
\hline Student x Rater & 588.663 & 25 & 23.54652 & 8.84 & 12.6 \\
\hline Student x Occasion & 281.971 & 25 & 11.27884 & 2.70616 & 3.8 \\
\hline Rater x Occasion & 23.087 & 1 & 23.087 & 0.66233 & 0.9 \\
\hline SRO,e & 146.663 & 25 & 5.86652 & 5.86652 & 8.3 \\
\hline
\end{tabular}

A small negative variance component was estimated for occasion (See Table 22) in the Classroom C SDQ Random s x r x o Model. Most of the variance (66.2\%) resulted from student differences, $13.2 \%$ for the residual, $12.7 \%$ for student by rater interaction, and $5.4 \%$ for rater and 
occasion. The remaining facets accounted for little variance.

Table 22

Classroom C SDQ Random sx r x o Model

\begin{tabular}{|c|c|c|c|c|c|}
\hline Sources of Variation & $\begin{array}{c}\text { Sums } \\
\text { of } \\
\text { Squares }\end{array}$ & df & $\begin{array}{c}\text { Mean } \\
\text { Squares }\end{array}$ & $\begin{array}{l}\text { Estimated } \\
\text { Variance } \\
\text { Component }\end{array}$ & $\begin{array}{c}\text { Percentage } \\
\text { of Total } \\
\text { Variance }\end{array}$ \\
\hline Student & 1019 & 26 & 39.19231 & 8.51566 & 66.2 \\
\hline Rater & 36.75 & 1 & 36.75 & 0.24145 & 1.9 \\
\hline Occasion & 14.083 & 1 & 14.083 & -0.12109 & 0 \\
\hline Student $x$ Rater & 129 & 26 & 4.96154 & 1.62892 & 12.7 \\
\hline Student $\mathrm{x}$ Occasion & 48.667 & 26 & 1.87181 & 0.08406 & 0.7 \\
\hline Rater x Occasion & 20.454 & 1 & 20.454 & 0.69446 & 5.4 \\
\hline $\mathrm{SRO}, \mathrm{e}$ & 44.296 & 26 & 1.70369 & 1.70369 & 13.2 \\
\hline
\end{tabular}

Comparing random s x $\mathbf{r} \times$ o models. Across screeners and occasions, the largest percentage of rating variance was attributable to the facet of students $(54.8-71.5 \%)$. Similarly, the residual term (Rater by student by occasion, plus any additional error) ranged from 6.3 to 13.2\% across scales, classrooms, and measures. The student by rater interactions accounted for the next largest percentage of variance $(8.9-16.3 \%)$ of variance across scales and classrooms. When comparing the SAEBRS and SDQ, the percentage of variance for the estimated variance components appears to be most similar across Classrooms A and B. However, the Classroom B rater facet for the SAEBRS accounted for approximately four times the variance of the rater facet on the SDQ. When comparing classrooms, the rater facet of Classrooms A and B ranged from 5 to $21.6 \%$ for both screening measures, while Classroom $\mathrm{C}$ ranged from .02 to $1.9 \%$. This suggests that rater effects were present in Classrooms A and B. Similarly, the presence of rater by student interaction effects suggests some level of rater bias in the scores of each respective screener (see Table 23). 
Table 23

Summary of Percentages of SDQ and SAEBRS Random s x r x o Model

\begin{tabular}{|c|c|c|c|c|c|c|}
\hline \multirow{3}{*}{$\begin{array}{c}\text { Sources of } \\
\text { Variation }\end{array}$} & \multicolumn{6}{|c|}{ Percentage of Variance } \\
\hline & \multicolumn{2}{|c|}{ A } & \multicolumn{2}{|c|}{$\mathrm{B}$} & \multicolumn{2}{|c|}{$\mathrm{C}$} \\
\hline & SAEBRS & SDQ & SAEBRS & SDQ & SAEBRS & SDQ \\
\hline Student & 62.8 & 71.5 & 54.8 & 65 & 71.7 & 66.2 \\
\hline Rater & 14.3 & 9.2 & 21.6 & 5 & 0.2 & 1.9 \\
\hline Occasion & 0.2 & 0.1 & 2.1 & 4.3 & 0.7 & 0 \\
\hline Rater x Student & 11.6 & 8.9 & 12.4 & 12.6 & 16.3 & 12.7 \\
\hline Rater x Occasion & 0 & 0 & 2.5 & 3.8 & 1.7 & 0.7 \\
\hline Student x Occasion & 0 & 0 & 0.3 & 0.9 & 0.6 & 5.4 \\
\hline Residual (RSO,e) & 11.2 & 10.4 & 6.3 & 8.3 & 8.8 & 13.2 \\
\hline
\end{tabular}

\section{Decision Studies}

To address research question three, described below are decision studies examining rater and occasion were conducted to examine what conditions of measurement may result in the the most generalizable data.

Decision study for occasion on step two (mixed $\mathbf{s} \times \mathbf{r} \times \mathbf{0}$ m) models. A minimum of 2 occasions (i.e., fall and spring screening administrations) were required for resulting $\rho^{2}$ values (see Table 24) to reach an acceptable level of reliability for low stakes relative decision making (.70; Salvia et al., 2010). This was consistent for all three classrooms. Resulting $\rho^{2}$ values did not reach the .80 criterion until the fifth and ninth screening occasions for Classroom $\mathrm{C}$ and Classroom B, respectively. 
Table 24

Occasion Decision Studies for Mixed s x r x o x m Model

\begin{tabular}{|c|c|c|c|c|c|c|c|c|c|c|c|}
\hline & G Study & \multicolumn{10}{|c|}{ D Study } \\
\hline & \multicolumn{11}{|c|}{ Number of Raters } \\
\hline & 2 & 1 & 1 & 1 & 1 & 1 & 1 & 1 & 1 & 1 & 1 \\
\hline & \multicolumn{11}{|c|}{ Number of Measures } \\
\hline & 2 & 1 & 1 & 1 & 1 & 1 & 1 & 1 & 1 & 1 & 1 \\
\hline & \multicolumn{11}{|c|}{ Number of Occasions } \\
\hline Classroom & 2 & 1 & 2 & 3 & 4 & 5 & 6 & 7 & 8 & 9 & 10 \\
\hline$A \rho^{2}$ & .96 & .82 & .88 & .91 & .92 & .93 & .93 & .94 & .94 & .94 & .94 \\
\hline$B \rho^{2}$ & .90 & .73 & .76 & .78 & .78 & .79 & .79 & .79 & .79 & .80 & .80 \\
\hline$C \rho^{2}$ & .94 & .69 & .75 & .78 & .79 & .80 & .80 & .81 & .81 & .81 & .81 \\
\hline
\end{tabular}

Decision study for rater on step two (mixed $\mathrm{x}$ x $\mathrm{r}$ x 0 x m) models. The minimum number of raters required to demonstrate an acceptable level of reliability for low stakes relative decision making was one rater (i.e., teacher). The high stakes .80 criteria was surpassed when the sample size of raters was increased to two teachers in all classrooms, except Classroom C, which required three raters (see Table 25).

Table 25

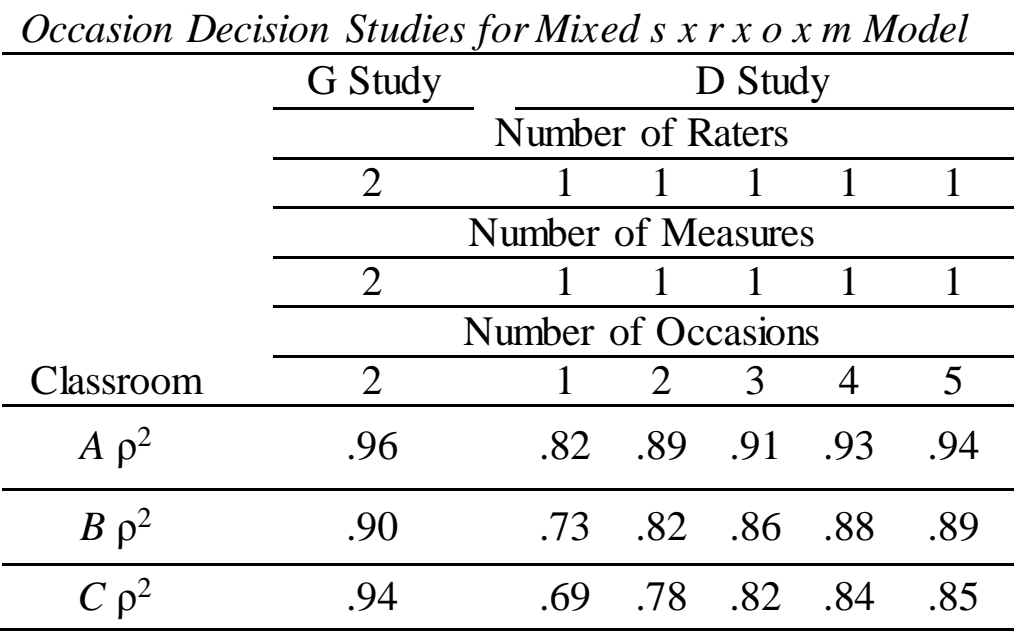

Decision study for occasion on step three (random $\mathbf{s} \times \mathbf{r} \times 0$ ) models. $\rho^{2}$ for both screeners in all three classrooms surpassed the .70 criteria for low stakes decision making with 
only a single rating occasion. However, more screening occasions were required for $\rho^{2}$ values to surpass the .80 criteria for the SAEBRS (see Table 26). As $\rho^{2}$ values for the SAEBRS Classroom $\mathrm{B}$ required three administrations of screening measures, Classroom $\mathrm{C}$ required five, and Classroom A required three. The SDQ required two for Classroom A, three for the Classroom B, and four for Classroom C.

Table 26

Decision Study for Occasion

\begin{tabular}{|c|c|c|c|c|c|c|c|c|c|c|c|}
\hline & G Study & \multicolumn{10}{|c|}{ D Study } \\
\hline & \multicolumn{11}{|c|}{ Number of Raters } \\
\hline & 2 & 1 & 1 & 1 & 1 & 1 & 1 & 1 & 1 & 1 & 1 \\
\hline & \multicolumn{11}{|c|}{ Number of Occasions } \\
\hline Measure & 2 & 1 & 2 & 3 & 4 & 5 & 6 & 7 & 8 & 9 & 10 \\
\hline \multicolumn{12}{|c|}{ Classroom A } \\
\hline SAEBRS $\rho^{2}$ & .88 & .73 & .79 & .8 & .81 & .82 & .83 & .83 & .83 & .83 & .83 \\
\hline $\operatorname{SDQ} \rho^{2}$ & .91 & .79 & .84 & .85 & .85 & .86 & .87 & .87 & .87 & .88 & .88 \\
\hline \multicolumn{12}{|c|}{ Classroom B } \\
\hline SAEBRS $\rho^{2}$ & .86 & .72 & .77 & .78 & .79 & .79 & .8 & .8 & .8 & .8 & .86 \\
\hline SDQ $\rho^{2}$ & .86 & .72 & .78 & .8 & .81 & .81 & .82 & .82 & .82 & .82 & .83 \\
\hline \multicolumn{12}{|c|}{ Classroom C } \\
\hline SAEBRS $\rho^{2}$ & .86 & .73 & .77 & .78 & .79 & .8 & .8 & .8 & .8 & .81 & .86 \\
\hline SDQ $\rho^{2}$ & .87 & .71 & .77 & .79 & .8 & .81 & .82 & .82 & .82 & .82 & .87 \\
\hline
\end{tabular}

Decision study for rater on step three (random $\mathbf{s} x \mathbf{r}$ x o) models. For all classrooms, the number of rater needed to surpass the .80 criteria was two for both screeners, even though all measures and classrooms met the .70 criteria using a single rater (see Table 27). Both screening measures performed similarly across all three classrooms. These results indicate that screening measures may benefit from the use of two raters (i.e., teachers). 
Table 27

Decision Studyfor Rater

\begin{tabular}{|c|c|c|c|c|c|c|c|}
\hline \multirow[b]{5}{*}{ Classroom } & \multirow[b]{5}{*}{ Measure } & G Study & \multicolumn{5}{|c|}{ D Study } \\
\hline & & \multicolumn{6}{|c|}{ Number of Raters } \\
\hline & & 2 & 1 & 2 & 3 & 4 & 5 \\
\hline & & \multicolumn{6}{|c|}{ Number of Occasions } \\
\hline & & 2 & 1 & 1 & 1 & 1 & 1 \\
\hline \multirow{2}{*}{ A } & SAEBRS $\rho^{2}$ & .88 & .73 & .85 & .89 & .92 & .93 \\
\hline & SDQ $\rho^{2}$ & .91 & .79 & .88 & .92 & .94 & .95 \\
\hline \multirow{2}{*}{ B } & SAEBRS $\rho^{2}$ & .86 & .72 & .82 & .86 & .88 & .9 \\
\hline & SDQ $\rho^{2}$ & .86 & .72 & .82 & .86 & .88 & .89 \\
\hline \multirow{2}{*}{$\mathrm{C}$} & SAEBRS $\rho^{2}$ & .86 & .73 & .83 & .88 & .9 & .91 \\
\hline & $\mathrm{SDQ} \rho^{2}$ & .87 & .71 & .83 & .88 & .9 & .92 \\
\hline
\end{tabular}




\section{Chapter V: Discussion}

In response to meeting students' academic and behavioral health needs, schools are increasingly using multi-tiered systems of supports (MTSS) to better identify and provide interventions to support students. Departing from traditional methods of identification, MTSS rely on the systematic collection and analyses of data to prevent the development of disorders and to improve systems of identification for students in need of further support. As much of the promise of MTSS and other surveillance-based methods rely on universal screening procedures as the primary means in which data are initially gathered for individual students, research has sought to improve the efficiency and feasibility of data gathering procedures. To this end, BBRS are increasingly used by school professionals to quickly and efficiently assess students at-risk of behavioral and emotional concerns. As such, it is important that these measures are psychometrically sound.

To date, previous research has examined screening measures through examination of traditional reliability coefficients founded in classical test theory (CTT) and findings from the current study show that correlation coefficients examining interrater reliability, test-retest reliability, and concurrent validity for the two measures examined in the current study were generally strong. However, generalizability analyses from this investigation also indicated that the majority of variance in teacher ratings was attributable to student differences across all score comparisons, but differences between teacher ratings for particular students and between instruments accounted for relatively large percentages of error variance among student behavior ratings. The results of the decision studies were as expected, demonstrating that increasing the number of screening occasions and raters resulted in more generalizable data. Of interesting note, using two raters for a single screening occasion resulted in procedures that are not only 
more generalizable, but also require less teacher time and ultimately, school resources. The findings of $\mathrm{G}$ and $\mathrm{D}$ studies provide important considerations of how each facet may differentially affect the meaningfulness of scores and the generalizability of scores of universal screening measures.

\section{Research Question One: What is the test-retest, inter-rater reliability, and concurrent} validity of BBRS?

Test-rest reliability. Strong bivariate correlations between measurement occasions were observed. All test-retest correlation coefficients for this study, with the exception of a single teacher, were near or above the .80 criteria. No clear pattern was observed in the correlations when examined for measure, teacher, and classroom discrepancies. These results are similar to previous work examining the short-term stability of screening scores (see Dowdy, NylundGibson, Felix, Morovat, \& Dever, 2014 for a review). The results of correlational analyses suggest that screening multiple times each year (e.g., fall, spring) is not a significant source of measurement error.

Concurrent validity. Pearson product moment correlations comparing the SAEBRS and SDQ were strong, with most falling above .90. These correlations far surpassed the requirements for high stakes decisions and are similar to previous studies examining the concurrent validity of behavior rating scales (e.g., Bergeron et al., 2008; Goodman \& Goodman 2009; Kilgus et al, 2015; Muris et al. 2004; von der Embse et al., 2015). These results suggested that the SAEBRS and SDQ assess similar constructs as measurement error resulting from discrepancies between screening measures is low.

Inter-rater reliability. Correlational analyses using Spearman's rank correlation coefficient $(r h o)$ were near or above the .70 criteria for SAEBRS and SDQ scores across the 
three classrooms and occasions. However, when examining the entire sample, rho correlations were smaller $(.57-.67$ for SAEBRS; $.63-.85$ for the SDQ). A plausible reason for the lower correlations when all classes were examined is that rho does not account for the nested nature of the data when examining the entire sample (Langberg et al, 2010). Nevertheless, rater agreement analyses showed that teachers agreed on approximately 77 to $83 \%$ of cases, while disagreeing on 7 to $23 \%$ of cases, depending on teacher pair and screening measure used. Taken together, these results align with previous studies examining inter-rater reliability and found that some degree of error came from differences between raters (De Los Reyes \& Kazdin, 2005). As a follow-up, the precise nature of this error was then examined through G theory-based analyses, with subsequent $\mathrm{D}$ studies, providing a method to further examine sources of variance and error in school-based screening measures and procedures.

\section{Research Question Two: What proportion of variance in data derived from screening} scores is attributable to differences between students, teachers, occasions, measures, and/or the interactions between these factors?

Student differences. In general, the percentage of variance attributable student level differences accounted for the largest majority of total variance observed in scores. At most, this percentage accounted for $80.6 \%$ in the mixed s.r x o x m model. However, the nesting of student within rater (s:r) makes it impossible to discern the student main effect from the rater and student interaction. Therefore, this percentage is likely an overestimation of student level differences, as these variance components are summed together in the s:r x o x m model. Further analyses conducted on the models without the confounding effects of nesting revealed that student level differences also accounted for the vast majority of variance. The percentage of variance attributable to students accounted for 69 to $81 \%$ of the total variance in scores in the mixed s x r 
x o x m models. Similar percentages of variance were also noted for the SAEBRS (54.8 to $71.7 \%$ ) and SDQ (65 to $71.5 \%$ ) in the random s x r x o G studies. Although a range of differences were found to exist between classrooms and raters, especially when they were examined in isolation, the general pattern that most variance is attributable to the student facet holds true in all three levels of analyses.

These findings are highly desirable because they suggest that the largest contributor to the observed scores are the "real" or "true" differences in the trait of BER, which is not considered measurement error. Similar results were also found by Bergeron and colleagues (2008) when examining longer behavior rating scales, demonstrating a large percentage of variance was due to student differences. However, these findings were in contrast to findings by Wright and Piersel (1992) and Volpe et al. (2011), who found that student level differences only attributed a small amount of variance as compared to other facets. Additional research is needed to support initial findings that screening measures are able to detect differences in BER among students.

Occasions. G study results examining the screening occasions (e.g., fall, spring) demonstrated small score changes between Fall and Spring screening occasions, as little variance was attributable to the main effect of occasion. In fact, no variance was attributable to occasion in the mixed s:r x o x m model. Similarly, the percentage of variance attributable to occasion accounted for 0 to $0.1 \%$ of the total variance in the mixed $\mathrm{s} \times \mathrm{r} \times \mathrm{o} \times \mathrm{m} g$ studies. However, when the SDQ and SAEBRS were examined with random s x r x o G studies, the percentage of variance attributable to occasion were small (0-4.3\%), with slight variations between classrooms. This finding was also evident when data was examined qualitatively as, students identified at atrisk during the Fall screening continued to be rated as at-risk by teachers during Spring screening 
administration. These results show that BER levels remained relatively stable over screening occasions.

Measures. Generalizability analyses attributed little variance percentage to the main effect of measure. This finding was also similar to those of Bergeron et al., (2008), who also found that little variance was attributable to measure. Although the random s x r x o model did not include a measure facet, the SAERBS and SDQ attributed similar percentages of variance to student level differences, other relevant main effects, and interactions. These results are promising, given that both measures are designed to assess BER among school-aged students.

Teachers (rater). Generalizability analyses showed a low percentage of variance was attributable to rater main effects for the mixed s:r $\mathrm{x}$ o $\mathrm{x} \mathrm{m}$ and mixed $\mathrm{s} \times \mathrm{r}$ x o x m models. The results suggested that special education and general education teachers produced a similar pattern of differences in scores and is consistent with other studies similar examining rater effects with G theory (e.g., Bergeron et al., 2008). In contrast, models examining the SDQ and SAEBRS (random s x r x o models) independently attributed a larger percentage of variance to the scores generated by each teacher. For example, Classrooms A and B attributed more variance (5$21.6 \%$ ) to the teacher, depending on screener used. However, teachers in Classroom $\mathrm{C}$ contributed significantly less variance $(.02-1.9 \%)$ to the overall model. Differences between model types may result from the use of z-scores calculated for each teacher within the fall and spring occasions, which may have truncated the range of scores.

Teacher differences were also evident in descriptive analyses, as special education teachers rated students as having lower levels of BER, with lower variability in their range of scores. For example, special education teachers raw scores ranged from 22 to 57 on the SAEBRS, while general education teachers scores ranged from 6 to 57 . A similar pattern is also 
present in the scores of the SDQ. Special education teacher means were significantly lower than their general education co-teacher. Furthermore, base rate analyses revealed that the percentage of students identified as as risk by special education teachers were approximately half of the number of students rated as at-risk by general education teachers. Taken together, these results indicated that teachers may be meaningful contributors of systematic variance between students.

Interactions. An important consideration in universal screening practices is the examination of student by rater interaction, as it may indicate that raters may use different standards in applying the BBRS (Hoyt \& Kerns, 1999). The current study approaches rater bias from a psychometric standpoint (i.e., rater bias is a source of error variance), and cannot comment on rater bias resulting from an interaction due various student characteristics (e.g., race, ethnicity, gender) and teacher characteristics (e.g., perceptions regarding student behavior). However, rater bias may occur when teachers are rating the same student as having either higher or lower frequencies of BER (e.g., indicating halo or leniency effects; Hoyt \& Kerns, 1999). For the s x r o x m model, the student by rater interaction accounted for 0 to $12.6 \%$ of variance. In $G$ studies, approximately 9 to $16 \%$ of the observed variance was found in the rater by student interaction across both screening measures, indicating some differences in student risk scores can be attributed to the scores students as rated by one teacher disagreeing from those of the other. This is perhaps most evident when examining inter-rater agreement, as teachers displayed disagreement in their identification of at-risk students.

Other interactions that produced significant amounts of error variance were seen in the three-way interaction between student, rater, and measure in the mixed s x r x o m models (values ranging from $1.1-4.9 \%$ ). However, the most significant percentage of variance associated with the occasion facet was the three-way interaction of student, rater, and occasion in 
the mixed s x r x o x m model, which accounted for 5.2 to $12.9 \%$ of variance. This suggested that when combining these variables, differences between Fall and Spring screening administrations may have led to some variability in student scores. However, it is important to note that it is difficult to interpret three way interactions because it is not clear how the amount of variance explained by one variable varies as a function of the remaining variables in the interaction (Cronbach et al, 1972), so results should be interpreted with caution.

Research Question Three: How does altering the number of raters and occasions affect the generalizability of universal screening scores?

Decision (D) studies were used to identify how the number of raters and occasions affect the meaningfulness of data derived from screening procedures, as evidenced by changes to the resulting generalizability coefficients $\left(\rho^{2}\right)$. D studies that examined the effect of increasing the number of screening occasions (e.g., Fall, Spring), while holding the number of measures and raters (i.e., teachers) to a sample size of one, showed that generalizability coefficient met or exceeded the criterion for low-stakes decisions (.70) with a single screening occasion, which is desirable in certain contexts. Although generalizability coefficients increased as the number of screening occasions increased, the criterion (.80) appropriate for contexts that view the decisions made as a result of screening was much harder to meet, with the majority of classrooms requiring an unrealistic number of screening administrations (e.g., greater than three times) to meet this criterion. Given the relative stability of screening scores through time as assessed in research questions one and two, these results demonstrate that increasing the number of times screening measures are administered may not be the most effective way of maximizing the generalizability of data. 
In contrast, $\mathrm{D}$ studies examining the effect of increasing the number of raters while holding the sample size of measure and occasion to one, proved an expedited method of maximizing the generalizability of data. Results of both D studies found that the more stringent criteria (.80) for when screening results are used in higher stakes decisions was surpassed with a measurement procedure that asked two teachers to complete a single screening measure at one point in time. Taken together, these results align with the correlational and generalizability analyses described above, demonstrating strong correlations in ratings between teachers at Fall and Spring screening administrations.

\section{Implications for Practice}

The current study builds upon the existing research base examining the use of BBRS within universal screening practices in several important ways. First, this study adds to the growing body of literature supporting the technical adequacy of data derived from screening procedures. To the author's knowledge, this is the first study to use $G$ theory to examine BBRS for use in school-based universal screening practice. In general, CTT-based findings found testretest reliability, concurrent validity, and interrater reliability coefficients were strong, aligning with previous research examining the psychometric properties of screening measures used in the current study (e.g., Eklund et al., in press; Goodman \& Goodman, 2009; Kilgus et al., 2014). However, the current study extends upon previous literature by examining the reliability of screening data through a multifaceted view of measurement error. Results of generalizability analyses demonstrated that the vast majority of variance was attributable to the student differences (Glover \& Albers, 2009; Kettler et al., 2014). As a result, schools can be better assured that screening procedures are generating data that is meaningful because it speaks more 
to the expected student-level differences when examining BER than the error contribution resulting from different occasions, raters, and measures.

The second implication for practice relates to findings from test-retest and generalizability analyses examining occasion. As guidelines regarding the number of times screening measures should be administered over the course of one school year vary in the current literature (e.g., Chafouleas, Kilgus, \& Wallach, 2010; Dowdy et al., 2014; Ennis, Lane, \& Oakes, 2012), results examining occasion indicate that students were remarkably invariant. This may be the result of two reasons: (1) students' levels of BER from fall to spring were stable; and/or (2) teachers' perceptions of their students BER was relatively stable. While there is previous research demonstrating short-term stability of screening scores (Dowdy et al., 2014; Levitt et al., 2007), generalizability analyses examining occasion are unable to address the stability of screening scores over time. This is because $\mathrm{G}$ theory views dates as being randomly sampled from a larger universe, without regard to the nature of the temporal relationship between dates. However, the finding that scores varied little from fall to spring, suggests that it may be reasonable for schools to adjust the number of screening occasions (i.e., by increasing the length of screening intervals or decreasing the number of screening occasions conducted per year) in future screening considerations.

The third implication relates to rater variance. Error variance stemming from rater main effects and rater interactions supports the notion that rater selection is an important consideration in school-based universal screening procedures. This is because two different teachers may generate data that is substantially different enough to affect identification decisions about individual students (Chafouleas et al., 2010). Teacher differences may result from differing opinions of the severity of student behavior and/or the frequencies with which these behaviors 
occur (De Los Reyes \& Kazdin, 2005). However, one way of reducing this type of error involves strategies to better equip raters with the information they need to make accurate assessments of student behavior. This could include implementation of rater training prior to the administration of screening measures (Chafouleas et al., 2012), further assisting teachers with an understanding of normative student behavioral expectations. While training would substantially increase the time and school resources required to complete screening, it may best ensure that schools have quality data in which to make treatment decisions, further minimizing rater bias (Volpe et al., 2012).

As BBRS typically require ratings from an outside source to assess student behavior, it may be impossible to fully escape error variance stemming from differences between raters. As a result, the fourth implication for practice suggests that schools embrace rater differences. D study results demonstrated that two raters significantly improved the generalizability of scores, schools may want to consider the use of a second teacher, or perhaps a second informant (e.g., parent, self-report data) to improve the generalizability of results. This finding has been supported by a substantial literature base suggesting multiple informants often provide more comprehensive data than those relying on one piece of supporting evidence (e.g., Merrill \& Whitcomb, 2012). While it may be difficult to coordinate data collection using multiple raters (e.g., parents, teachers), current results suggest schools can enhance the accuracy of screening results by using multiple informants.

Finally, the strong concurrent validity between the screening measures used in the current study and the small amount of variance attributed to the selected screening measure, provides schools with some choice in their selection of screening measures. Although schools may want to consider a number of important factors in this decision, such as (a) length of the measure, (b) 
constructs of interests, and (c) how data will be used to guide the selection of interventions in schools, selecting a shorter screening measure may is certainly a valid concern when considering time required by teachers to screen an entire classroom.

\section{Limitations}

Despite efforts to identify and minimize potential limitations in the current study, threats to the generalizability of these findings were noted. First, the current study included six raters across three classrooms, primarily because of their ability to: (1) rate the same students across the same subject and time of day in their classroom; while (2) holding the classroom variable constant. Thus, these participants represented a sample of convenience. As G theory assumes that instances of a random facet have been randomly sampled from a larger universe of rater, the argument could be made that it is inappropriate to generalize the results of the current study to a larger universe of raters. The decision was made to treat rater as random because (1) it was reasonable to assume that the teachers in the current study would provide acceptable observations (ratings), (2) the six teachers do not represent the entirety of the universe of acceptable raters for use in screening procedures and (3) it enables the estimation of variance components that are of interest in the current study (i.e., rater main effect and rater by student interaction).

Second, the use of three special education teachers and three language arts teachers across three classrooms also limits generalizations that can be made about the data. The use of these co-taught classrooms did not allow for the ability to sort out differences between raters (e.g., special education, general education teachers) due to a small sample size. It is plausible that any results involving rater variance may stem from the types of ratings that special education teachers may attribute to student behavior compared to their general education counterparts. As 
behavior rating involves making a comparison (presumably against some form of schema or personae about the normalcy and frequency of key behaviors; Nisbett \& Ross, 1980), a teacher's training, background, and experience may alter their conceptualization of behaviors that are perceived of as more or less normative (Gorman, \& Rentsch, 2009). For example, a special education teacher who works with students with behavioral concerns may perceive more disruptive behaviors as within the realm of normative behavior because they have more experience addressing these concerns in the classroom. In this case, their training and background experiences will likely influence their ratings.

Although the sample size of raters participating in the current study was larger than several previous studies using generalizability theory to examine rating scales (e.g., Bergeron et al., 2008; Volpe et al., 2011), the third limitation concerns the sample size for G and D studies examining the mixed $\mathrm{s} \times \mathrm{r}$ o x m and random $\mathrm{s} \times \mathrm{r}$ x o models. It is possible that unstable variance components were estimated, as they were based on the ratings of only two teachers. Future studies should consider using a larger sample of co-taught classrooms to ensure the generalizability of study results. However, this study carefully weighted the advantages of using a fully crossed crossed design, which enabled the calculation of the student by rater interaction, distinct student main effect, and distinct rater main effect. Furthermore, the feasibility of collecting fully crossed data (e.g., it is not feasible nor to have all teachers in a school rate all the students), represents the "Achilles heel of G theory" (Shavelson \& Webb, 1981, p. 138), in which the stability of variance components for classrooms may be called into question for nonnested analyses. Yet, the results of the current study showed multiple similarities between the nested and non-nested models and support that general interpretations can be drawn from analyses examining individual classrooms (Smith, 1981). 
And finally, population characteristics constrained the generalization of results. As the secondary participants in the current study were selected from language arts classrooms in a single school from the southwestern United States, made up of a predominantly Caucasian student sample, results may not be generalizable to other populations. As a result, the current study cannot speak to the qualities of data derived from students with greater racial/ethnic diversity and in other academic contexts and/or communities. Future research is needed to examine study questions among students with greater racial/ethnic diversity and in other academic contexts and/or communities.

\section{Future Research}

Given the limitations of the current study and a general lack of $\mathrm{G}$ studies examining universal screening procedures, additional areas of research are needed to better understand the nature of measurement error data derived from universal screening procedures. First, this study could be extended into high schools and elementary schools. This would provide information regarding the generalizability of data for students at varying levels of education and if the proportion of variance attributable to students, raters, occasions, and methods differs depending on the grade level of students being assessed. This might be expected as the developmental expectations for younger and older students are markedly different, and therefore teacher ratings may change.

Second, as screening results may differ depending on the content in which they are obtained, screening data obtained in different subjects may have varying levels of generalizability. As such, it may prove beneficial to examine other types of subjects, such as math, science, physical education, or art. This could be examined with the addition of subject facet, and may provide valuable insight into how different environments may influence 
measurement error between scores.

Third, future research may want to examine how different types of raters contribute error. For example, self, parent, and teacher raters could be included in future analyses. As students develop cognitively and behaviorally, they may become more reliable informants of their own behavior. If large differences are noted between self and teacher/parent ratings, then additional analyses would be needed to determining the reliability of each rater.

Lastly, future research should consider how characteristics of individual teachers and their professional relationship with their respective co-teacher may affect the level of rater agreement. It is conceivable that two factors may potentially impact teacher's ratings of students, including (a) number of years of teaching experience, and (b) number of years each coteaching team has been working together. Implicit in teacher ratings is normative comparisons between teachers, such that teachers with more experience may better understand normative student behavior compared to their less experienced peers. Thus, inexperienced teachers may be less able to recognize concerning student behaviors, or what behaviors are more or less severe. The length of the co-teaching relationship may also influence teacher rater agreement, as teachers who have been working collaboratively for a longer period of time may show more agreement than teachers with fewer years of experience working together.

\section{Conclusion}

The current investigation examined the technical adequacy of BBRS within universal screening procedures for behavioral and emotional risk within schools. Generalizability analyses were used to examine the extent to which various components contribute measurement error in ratings of BER. Results indicated that the selection of measures and screening occasions contributed less measurement error than did rater. Furthermore, some evidence of rater bias was 
revealed to contribute to the variance in obtained screening scores. However, most of the variance was a result of the differences that exist between students on BER. These findings are encouraging as they provide additional support for the use of BBRS as a psychometrically sounds and efficient method of identifying students at-risk of behavioral and emotional concerns in schools. 


\section{REFERENCES}

Achenbach, T. M., \& Rescorla, L. A. (2001). Manual for the ASEBA school-age forms \& profiles. Burlington, VT: University of Vermont, Research Center for Children, Youth, \& Families.

Albers, C. A., Glover, T. A., \& Kratochwill, T. R. (2007). Where are we, and where do we go now? Journal of School Psychology, 45(2), 257-263. doi: 10.1016/j.jsp.2006.12.003

American Educational Research Association, American Psychological Association, and National Council on Measurement in Education. (1999). Standards for educational and psychological testing. Washington, DC: Author.

Aronson, E., Ellsworth, P. C., Carlsmith, J. M., \& Gonzales, M. H. (1990). Methods of research in social psychology. New York: McGraw-Hill.

Bergeron, R., Floyd, R. G., McCormack, A. C., \& Farmer, W. L. (2008). The generalizability of externalizing behavior composites and subscale scores across time, rater, and instrument. School Psychology Review, 37, 91-108.

Bloch, R., \& Norman, G. (2012). Generalizability theory for the perplexed: A practical introduction and guide: AMEE guide number 68. Medical Teacher, 34(11), 960-992. doi: 10.3109/0142159X.2012.703791

Bradley, R., Doolittle, J., \& Bartolotta, R. (2008). Building on the data and adding to the discussion: The experiences and outcomes of students with emotional disturbance. Journal of Behavioral Education, 17, 4-23. doi:10.1007/s10864-007-9058-6

Brennan, R. L. (2001). Generalizability theory. New York, NY: Springer-Verlag Brennan, R. L. (2011). Generalizability theory and classical test theory. Applied Measurement in Education, 24, 1-21. 
Briesch, A. M., Chafouleas, S. M., \& Johnson, A. J. (In press). Use of generalizability theory within k-12 school-based assessment: a critical review and analysis of the empirical literature. Journal of Applied Measurement in Education.

Briesch, A. M., Swaminathan, H., Welsh, M., \& Chafouleas, S. M. (2014). Generalizability theory: A practical guide to study design, implementation, and interpretation. Journal of School Psychology, 52(1), 13-35. doi: 10.1016/j.jsp.2013.11.008

Briesch, A. M., Volpe, R. J., \& Ferguson, T. D. (2014). The influence of student characteristics on the dependability of behavioral observation data. School Psychology Quarterly, 29(2), 171-181. doi: $10.1037 / \mathrm{spq} 0000042$

Bruhn, A. L., Woods-Groves, S., \& Huddle, S. (2014). A preliminary investigation of emotional and behavioral screening practices in k-12 schools. Education and Treatment of Children, 37(4), 611-634. doi: 10.1353/etc.2014.0039

Burks, H. F. (1977). Birks’ Behavior Rating Scales. Los Angeles: Western Psychological Services

Chafouleas, S. M., Kilgus, S. P., \& Wallach, N. (2010). Ethical dilemmas in school-based behavioral screening. Assessment for Effective Intervention, 35(4), 245-252. doi: $10.1177 / 1534508410379002$

Chafouleas, S. M., Volpe, R. J., Gresham, F. M., \& Cook, C. R. (2010). Models special series: Behavioral assessment within problem-solving school-based behavioral assessment within problem-solving models: Current status and future directions. School Psychology Review, 39, 343. 
Chin, J., Dowdy, E., \& Quirk, M. (2013). Universal screening in middle school: Examining the behavioral and emotional screening system. Journal of Psychoeducational Assessment, 31, 53-60. doi:10.1177/0734282912448137

Christ, T. J., Johnson-Gros, K., \& Hintze, J. M. (2005). An examination of computational fluency: The reliability of curriculum-based outcomes within the context of educational decisions. Psychology in the Schools, 42, 615-622.

Christ, T. J., \& Nelson, P. M. (2013). Developing and evaluating screening systems: Practical and psychometric considerations. In R. J. Kettler, T. A. Glover, C. A. Albers, \& K. A. Feeney-Kettler (Eds.), Universal screening in educational settings: Evidence-based decision making for schools (pp. 79-110). Washington: American Psychological Association. doi: 10.1037/14316-004

Cohen, J. (1988). Statistical power analysis for the behavioral sciences (2nd ed.). Hillsdale, NJ: $\underline{\text { Lawrence Earlbaum Associates. }}$

Cook, C. R., Volpe, R. J., \& Livanis, A. (2010). Constructing a roadmap for future universal screening research beyond academics. Assessment for Effective Intervention, 35(4), 197205. doi: $10.1177 / 1534508410379842$

Cone, J. D. (1977). The relevance of reliability and validity for behavioral assessment. Behavior Therapy, 8(3), 411-426. doi: 10.1016/s0005-7894(77)80077-4

Cowan, K. C., \& Vaillancourt, K. (2013). Advocating for safe schools, positive school climate, and comprehensive mental health services. Communiqué, 41(6). Retrieved from http://www.nasponline.org/publications/cq/41/6/advocacy-in- action.aspx

Crocker, L., \& Algina, J. (1986). Introduction to Classical and Modern Test Theory. New York: Harcourt Brace. 
Cronbach, L. J., Gleser, C. G., Rajaratnam, N., \& Nanda, H. (1972). The Dependability of Behavioral Measurements. New York, NY: Wiley.

Cronbach, L. J., \& Shavelson, R. J. (2004). My current thoughts on coefficient alpha and successor procedures. Educational and Psychological Measurement, 64(3), 391-418. doi: $10.1177 / 0013164404266386$

Cunningham, J. M., \& Suldo, S. M. (2014). Accuracy of teachers in identifying elementary school students who report at-risk levels of anxiety and depression. School Mental Health, 6(4), 237-250. doi: 10.1007/s12310-014-9125-9

Dowdy, E., Doane, K., Eklund, K., \& Dever, B. (2011). A comparison of teacher nomination and screening to identify behavioral and emotional risk. Journal of Emotional and Behavioral Disorders, 21(2), 127-137. doi:10.1177/1063426611417627.

Dowdy, E., Furlong, M., Eklund, K., Saeki, E., \& Ritchey, K. (2009). Screening for mental health and wellness: Current school-based practices and emerging possibilities. In B. Doll (Eds.), Handbook of Prevention Science (pp. 70-95). Bethesda, MD: National Association of School Psychologists.

Dowdy, E., Furlong, M., Raines, T. C., Bovery, B., Kauffman, B., \& Kamphaus, R. W. (2014). Enhancing school-based mental health services with a preventive and promotive approach to universal screening for complete mental health. Journal of Educational and Psychological Consultation, 25(2-3), 178-197. doi: 10.1080/10474412.2014.929951

Dowdy, E., \& Kim, E. (2012). Choosing informants when conducting a universal screening for behavioral and emotional risk. School Psychology Forum, 6(4), 98-107

Dowdy, E., Twyford, J., \& Sharkey, J. D. (2013). Methods of assessing behavior: observations and rating scales. In D. H. Saklofske, C. R. Reynolds, \& V. Schwean, Eds. The Oxford 
Handbook of Child Psychological Assessment (pp. 1-32). Oxford University Press. doi: 10.1093/oxfordhb/9780199796304.013.0026

Drummond, T. (1994). The student risk screening scale (SRSS). Grants Pass, OR: Josephine County Mental Health Program.

Dvorsky, R., Girio-Herrera, E., \& Owens, S., (2014). School-based screening for mental health in early childhood. In M. Weist., N. Lever., C. Bradshaw, \& J. Owens, Handbook of school mentalhealth. (pp. 297-310). New York, NY: Springer.

Eklund K., \& Dowdy, E. (2014). Screening for behavioral and emotional risk versus traditional school identification methods. School Mental Health, 6, 40-49.

Eklund, K., Renshaw, T. L., Dowdy, E., Jimerson, S. R., Hart, S. R., Jones, C. N., \& Earhart, J. (2009). Early identification of behavioral and emotional problems in youth: Universal screening versus teacher-referral identification. California School Psychologist, 14, 8995.

Eklund, K., \& Tanner, N. (2014). Providing multi-tiered systems of support for behavior: Conducting behavior screening at school. Principal Leadership, 10, 50-52.

Ennis, R. P., Lane, K. L., \& Oakes, W. P. (2012). Score reliability and validity of the student risk screening scale: A psychometrically sound, feasible tool for use in urban elementary schools. Journal of Emotional and Behavioral Disorders, 20, 241-259. doi: $10.1177 / 1063426611400082$

Forness, S. R., Freeman, S., Paparella, T., Kauffman, J. M., \& Walker, H. M. (2012). Special education implications of point and cumulative prevalence for children with emotional or behavioral disorders. Journal of Emotional and Behavioral Disorders, 20, 4-18. 
Glover, T. A., \& Albers, C. A. (2007). Considerations for evaluating universal screening assessments. Journal of School Psychology, 45, 117-135. doi: 10.1016/j.jsp.2006.05.005

Goodman, R. (1997). The strengths and difficulties questionnaire: A research note. Journal of Child Psychology and Psychiatry, 38, 581-586. doi: 10.1111/j.14697610.1997.tb01545.x

Goodman, R. (2004). Psychometric properties of the strengths and difficulties questionnaire. Journal of the American Academy of Child \& Adolescent Psychiatry, 40, 1337-1345. doi:10.1097/00004583-200111000-00015

Goodman, A., \& Goodman, R. (2009). Strengths and difficulties questionnaire as a dimensional measure of child mental health. Journal of the American Academy of Child \& Adolescent Psychiatry, 48, 400-403. doi:10.1097/ChI.0b013e3181985068

Individuals with Disabilities Education Improvement Act of 2004, 20 U.S.C. $\S 1400$ et seq. (2004). (Reauthorization of the Individuals with Disabilities Education Act of 1990)

Kamphaus, R. W. (2013). Screening for behavioral and emotional risk: Constructs and practicalities. School Psychology Forum, 6, 89-97.

Kamphaus, R., DiStefano, C., Dowdy, E., Eklund, K., \& Dunn, A. (2010). Defining the "problem" in problem solving models via universal screening for behavioral and emotional problems in schools. School Psychology Review, 39, 395-407.

Kamphaus, R. W., Dowdy, E., Kim, S., \& Chin, J. (2013). Diagnosis, classification, and screening systems. In D. H. Saklofske \& V. Schwean, (Eds.), Oxford Handbook of Psychological Assessment of Children and Adolescents (pp. 182-201). New York, NY: Oxford. 
Kamphaus, R. W., \& Reynolds, C. R. (2007). BASC-2: Behavioral and Emotional Screening System. San Antonio, TX: Pearson.

Kamphaus, R. W., Reynolds, C. R., \& Dever, B. V. (2013). Behavioral and mental health screening. In R. J. Kettler, T. A. Glover, C. A. Albers, \& K. A. Feeney-Kettler (Eds.), Universal screening in educational settings: Evidence-based decision making for schools (pp. 249-273). Washington: American Psychological Association. doi: 10.1037/14316010

Kern, L., Hilt-Panahon, A., \& Mukherjee, A. D. (2013). Strategies to address internalizing behavior problems. In B. Cook \& Tankersley, M. Research-based practices in special education (pp. 178-191). New Jersey: Pearson.

Kilgus, S. P., Chafouleas, S. M., \& Riley-Tillman, T. C. (2013). Development and initial validation of the social and academic behavior risk screener for elementary grades. School Psychology Quarterly, 28(3), 210-226. doi: 10.1037/spq0000024

Kilgus, S. P., \& Eklund, K. (2016). Consideration of base rates within universal screening for behavioral and emotional risk: A novel procedural framework. School Psychology Forum, 10, 120-130.

Kilgus, S. P., Reinke, W. M., \& Jimerson, S. R. (2015). Understanding mental health intervention and assessment within a multi-tiered framework: Contemporary science, practice, and policy. School Psychology Quarterly, 30, 159-165. doi: $10.1037 / \mathrm{spq} 0000118$

Kilgus, S. P., Sims, W. A., von der Embse, N. P, \& Riley-Tillman, T. C. (2014). Confirmation of models for interpretation and use of the social and academic behavior risk screener (SABRS). School Psychology Quarterly, 30, 335-352. doi:10.1037/spq0000087 
Lane, K. L., Menzies, H., Oakes, W., \& Kalberg, J. R. (2012). Systematic screenings of behavior to support instruction: From preschool to high school. New York: Guilford. doi: $10.1177 / 1044207310379123$

Lane, K. L., Oakes, W., \& Menzies, H. (2010). Systematic screenings to prevent the development of learning and behavior problems: Considerations for practitioners, researchers, and policy makers. Journal of Disability Policy Studies, 21, 160-172. doi: $10.1177 / 1044207310379123$

Loney, J., \& Milich, R. (1982). Hyperactivity, inattention, and aggression in clinical practice. In M. Wolraich \& D. K. Routh (Eds.), Advances in developmental and behavioral pediatrics (Vol. 3, pp. 113-147). Greenwich, CT: JAI.

Levitt, J. M., Saka, N., Hunter Romanelli, L., \& Hoagwood, K. (2007). Early identification of mental health problems in schools: The status of instrumentation. Journal of School Psychology, 45(2), 163-191. doi: 10.1016/j.jsp.2006.11.005

McIntosh, K., Frank, J. L., \& Spaulding, S. A. (2009). Establishing research-based trajectories of office discipline referrals for individual students. School Psychology Review, 39, 380394.

McIntosh, K., Reinke, W. M., \& Herman, K. C. (2010). School wide analysis of data for social behavior problems: Assessing outcomes, selecting targets for intervention, and identifying need for support. In G. G. Peacock, R. A. Ervin, E. J. Daly, \& K. W. Merrell (Eds.), Practical handbook of school psychology: Effective practices for the 21 st century (pp. 135-156). New York: Guilford Press. 
Menzies, H., \& Lane, K. L. (2012). Validity of the student risk screening scale: evidence of predictive validity in a diverse, suburban elementary setting. Journal of Emotional and Behavioral Disorders, 20(2), 82-91. doi: 10.1177/1063426610389613

Merikangas, K. R., He, J. P., Burstein, M., Swanson, S. A., Avenevoli, S., Chi, L., \& Swendsen, J. (2010). Lifetime prevalence of mental disorders in U.S. adolescents: Results from the National Comorbidity Survey Replication-Adolescent supplement (NCS-A). Journal of the American Academy of Child and Adolescent Psychiatry, 49, 980-989.

Merikangas, K. R., He, J. P., Burstein, M., Swendsen, J., Avenevoli, S., Case, B., ... Olfson, M. (2011). Service utilization for lifetime mental disorders in US adolescents: Results of the National Comorbidity Survey-Adolescent Suppl. (NCS-A). Journal of the American Academy of Child \& Adolescent Psychiatry, 50, 32-45. doi:10.1016/j.jaac .2010.10.006

Miller, F. G., Cohen, D., Chafouleas, S. M., Riley-Tillman, T. C., Welsh, M. E., \& Fabiano, G. A. (2014). A comparison of measures to screen for social, emotional, and behavioral risk. School Psychology Quarterly, 30, 184-196. doi: 10.1037/spq0000085

Mitchell, S. K. (1979). Interobserver agreement, reliability, and generalizability of data collected in observational studies. Psychological Bulletin, 86, 376-390.

Muris, P., Meesters, C., Eijkelenboom, A., \& Vincken, M. (2004). The self-report version of the Strengths and Difficulties Questionnaire: its psychometric properties in 8- to 13-year-old non-clinical children. British Journal of Clinical Psychology, 43, 437-448. doi:10.1348/0144665042388982.

Nisbett, R.E. \& Ross, L. (1980). Human Inference: Strategies and shortcomings of social judgment. ( Chp 2). Englewood cliffs, NJ: Prentice-Hall.

No Child Left Behind Act of 2001, 20 U.S.C. $§ 6301$ et seq. (2002). 
Poncy, B. C., Skinner, C. H., \& Axtell, P. K. (2005). An investigation of the reliability and standard error of measurement of words read correctly per minute using curriculumbased measurement. Journal of Psychoeducational Assessment, 23, 326-338.

Predy, L., McIntosh, K., \& Frank, J. L. (2014). Utility of number and type of office discipline referrals in predicting chronic problem behavior in middle schools. School Psychology Review, 43(4), 472-489.

Ree, M. J., \& Carretta, T. R. (2006). The role of measurement error in familiar statistics. Organizational Research Methods, 9(1), 99-112. doi: 10.1177/1094428105283192

Renshaw, T. L., Eklund, K., Dowdy, E., Jimerson, S. R., Hart, S. R., Earhart Jr, J., \& Jones, C. N. (2009). Examining the relationship between scores on the Behavioral and Emotional Screening System and student academic, behavioral, and engagement outcomes: An investigation of concurrent validity in elementary school. The California School Psychologist, 14(1), 81-88.

Reynolds, C. R., \& Kamphaus, R. W. (2004). Behavior Assessment System for Children (2nd ed.). Circle Pines, MN: AGS Publishing.

Romer, D., \& McIntosh, M. (2005). The roles and perspectives of school mental health professionals in promoting adolescent mental health. In D. L. Evans, E. B. Foa, R. E. Gur, H. Hendin, C.P. O’Brien, M. E. P. Seligman, \& B. T. Walsh (Eds.), Treating and preventing adolescent mental health disorders: What we know and what we don't know (pp. 598-615). New York, NY: Oxford University Press.

Salvia, J., Ysseldyke, J. E., \& Bolt, S. (2010). Assessment in special and inclusive education (11th ed.). Belmont, CA: Wadsworth 
Severson, H. H., Walker, H. M., Hope-Doolittle, J., Kratochwill, T. R., \& Gresham, F. M. (2007). Proactive, early screening to detect behaviorally at-risk students: Issues, approaches, emerging innovations, and professional practices. Journal of School Psychology, 45(2), 193-223. doi: 10.1016/j.jsp.2006.11.003

Shavelson, R. J., \& Webb, N. M. (1981). Generalizability theory: 1973-1980. British Journal of Mathematical And Statistical Psychology, 34, 133-166.

Shavelson, R. J. \& Webb, N. M. (1991). Generalizability theory: A primer. Newbury Park; CA: Sage Publications.

Shavelson, R. J., Webb, N. M., \& Rowley, G. L. (1989). Generalizability theory. American Psychologist, 44, 922-932.

Sireci, S. G. (1998). The construct of content validity. Social Indicators Research, 45(1-3), 83117.

Soles, T., Bloom, E. L., Heath, N. L., \& Karagiannakis, A. (2008). An exploration of teachers' current perceptions of children with emotional and behavioural difficulties'. Emotional and Behavioural Difficulties, 13, 275-290. doi:10.1080/13632750802442201.

Stein, B., Jaycox, L., Kataoka, S., et al. (2003). A mental health intervention for school children exposed to violence: A randomized controlled trial. Journal of the American Medical Association, 290, 603-611.

Sugai, G., \& Horner, R. H. (2006). A promising approach for expanding and sustaining schoolwide positive behavior support. School Psychology Review, 35, 245-259.

Volpe, R. J., Briesch, A. M., \& Gadow, K. D. (2011). The efficiency of behavior rating scales to assess inattentive-overactive and oppositional-defiant behaviors: Applying 
generalizability theory to streamline assessment. Journal of School Psychology, 49(1), $131-155$.

Walker, H. M., \& Severson, H. H. (1990). Systematic Screening for Behavior Disorders (SSBD). Longmont, CO: Sopris West.

Wright, D., \& Piersel, W. C. (1992). Components of variance in behavior ratings from parents and teachers. Journal of Psychoeducational Assessment, 10(4), 310-318. doi: $10.1177 / 073428299201000401$

Whitcomb, S. A., \& Merrell, K. (2012). Behavioral, social, and emotional assessment of children and adolescents (4th ed.). New York, NY: Routledge. 